Check for updates

Cite this: RSC Adv., 2022, 12, 6683

Received 6th December 2021 Accepted 4th February 2022

DOI: $10.1039 / \mathrm{d} 1 \mathrm{ra0} 8858 \mathrm{k}$

rsc.li/rsc-advances

\section{Assessment of greenness for the determination of voriconazole in reported analytical methods}

\begin{abstract}
Hemanth Kumar Chanduluru (D) and Abimanyu Sugumaran (DD*
Analytical research with adverse environmental impact has caused a severe rise in concern about the ecological consequences of its strategies, most notably the use and emission of harmful solvents/ reagents into the atmosphere. Nowadays, industries are searching for the best reproducible methods. Voriconazole is a second-generation azole derivative used effectively in the treatment of Candida and Aspergillus species infections and oropharyngeal candidiasis in AIDS patients. Recently it has become the drug of choice in treating mucormycosis in several countries, which raises the need for production in large quantities. The present review deals with various recent important analytical techniques used to estimate voriconazole and its combination in pharmaceutical formulations and biological fluids. The methods show their own unique way of analyzing voriconazole in different matrices with excellent linearity, detection, and quantification limits. Additionally, this article deals with methods and solvents analyzed for their impact on the environment. This is followed by estimating the degree of greenness of the methods using various available assessment tools like analytical eco-scale, national environmental method index, green analytical procedure index, and AGREE metrics to confirm the environmental impact. The scores obtained with the evaluation tools depict the quantum of greenness for the reported methods and provide an ideal approach adopted for VOR estimation. Very few methods are eco-friendly, which shows that there is a need for the budding analyst to develop methods based on green analytical principles to protect the environment.
\end{abstract}

SRM College of Pharmacy, SRM Institute of Science and Technology, Kattankulathur, 603203, India.E-mail: abipharmastar@gmail.com; abimanys@srmist.edu.in; Tel: +91 7904062599

\section{Introduction}

Developing analytical methods to determine medicines in bulk or pharmaceutical dose form is never an easy endeavour due to chemical complexity and variety. Many attempts have been made by analytical scientists from a variety of sectors to produce an individual robust analytical technique that is also compliant

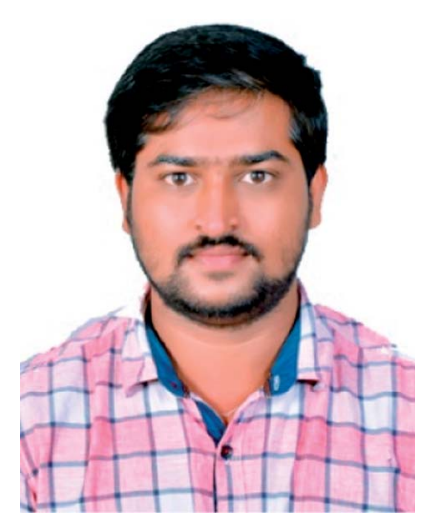

CH Hemanth Kumar is a PhD Scholar at the SRM Institute of Science and Technology, Chennai, India. He received his Master's degree in Pharmaceutical Analysis in 2014. He worked as an Assistant Professor in Aditya Pharmacy College until the year 2020 at the JNTUK, India, before being accepted for the PhD program. His main area of research focuses on the analysis of pharmaceuticals in their respective dosage forms and biological matrixes using green analytical chemistry principles and analytical quality by design.

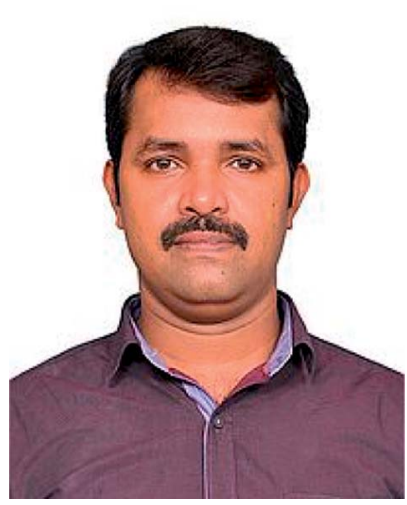

Dr Abimanyu Sugumaran received his $P h D$ from Anna University, Chennai, India, in 2015. He was appointed as a Professor in 2016 at the SRM College of Pharmacy, SRM Institute of Science \& Technology, Kattankulathur, India. His research interests mainly focus on novel drug delivery systems, polymeric and lipid nanoparticles, stimuliresponsive drug targeting, nano drug delivery, application of nanocarriers with various solid tumors and other lifestyle diseases and applications of green principles with newer analytical developments. 
with regulatory requirements. Regulators are increasingly seeking eco-friendly techniques to reduce or eliminate the formation of harmful effluents due to pollution created by analytes, solvents, and chemicals used in analytical departments. It is the purpose of this study to discuss different modern and essential analytical methods that have been developed to estimate voriconazole and its combination in pharmaceutical formulations and biological fluids, as well as the degree of greenness of the same.

\subsection{Voriconazole}

Voriconazole (VOR) is chemically ( $2 R, 3 S)$-2-(2,4-difluorophenyl)3-(5-fluoro-4-pyrimidinyl)-1-(1H-1,2,4-triazol-1-yl)-2-butanol

(Fig. 1). It works by inhibiting the fungal 14-alpha-lanosterol demethylation cytochrome P450-dependent 14-sterol demethylase, a vital enzyme in ergosterol biogenesis required to form fungal cell walls. ${ }^{\mathbf{1 - 4}}$

VOR has become an essential drug for treating mucormycosis or black fungus in the initial stages of their existence as well as SARS-CoV-2. VOR is also used for people diagnosed with Candida and Aspergillus species infection, which have death rates of more than $60 \%$. In addition, they are more likely to develop candidemia, leading to resistance to triazole antifungal drugs if not appropriately treated. ${ }^{5}$ While there are several treatment alternatives, currently available antifungal medicines do not meet the needs of many patients, especially those who take their medication by oral administration or through intravenous injection. Voriconazole (VOR) is the most critical triazole antifungal drug to enter the arsenal of antifungal agents. It has a structure similar to that of fluconazole and an activity spectrum comparable to that of itraconazole. In May 2002, the FDA approved VOR to treat Fusarium species refractory Scedosporium apiospermum and invasive aspergillosis infections. VOR has also been shown to be a promising drug for empiric treatment of febrile neutropenia in studies. ${ }^{6}$ The Jing Wang et al. study revealed that VOR is effectively used as the best prophylaxis option for patients undergoing hematopoietic stem cell transplantation. ${ }^{7}$ Voriconazole has high bioavailability (96\%) and has been shown to penetrate various eye areas, with adequate concentrations obtained to cover a wide variety of keratitis-causing fungi. Voriconazole eye drops, produced ad hoc and then used off-label, have been recommended successfully to treat keratitis. Voriconazole showed adequate penetration via the cornea into the aqueous

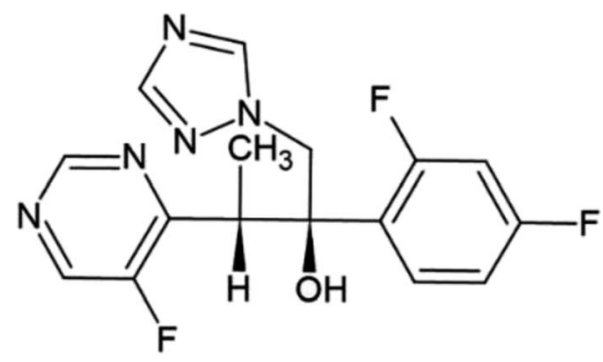

humour after topical treatment without affecting intraocular tolerability. ${ }^{\mathbf{2}}$

VOR is available in different dosage forms for the treatment of many fungal infections. Analytical techniques are used throughout the drug development process, from pre-clinical to post-clinical testing, to understand the drug's physical and chemical stability, impact on dosage form selection and design, and quantification of impurities. Various technological enhancements in separation science, modern sophisticated spectroscopic and liquid chromatographic techniques, and the use of bioanalytic tools for molecular recognition and testing have been of great advantage to pharmaceutical analysis in recent years. The whole dosage form development process requires effective, precise analytical procedures to support every step. Pharmaceutical companies are obliged to use the most accurate, prudent, and dependable quality control methods to quantify VOR. The reported best analytical methods for estimating VOR present in different pharmaceutical dosage forms are highlighted to illustrate the importance of VOR analyses (Fig. 2 and 3).

Analytical methods such as chromatographic techniques utilize toxic solvents and have a deleterious effect on the environment.

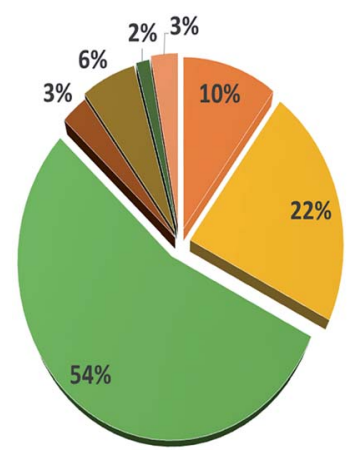

Spectroscopic HPLC

Bioanalytical

- AQbD

- HPTLC

Microbiological

other

Fig. 2 Methods available for the estimation of VOR.

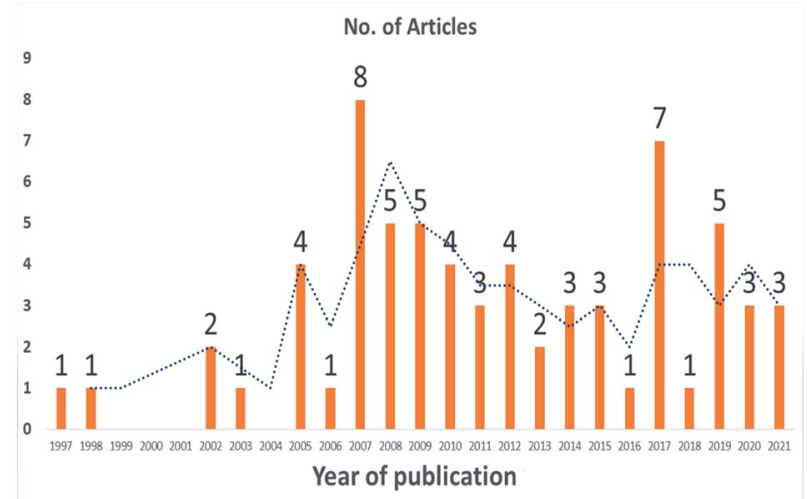

Fig. 3 Analytical methods reported for VOR from 1997 to September 2021 (source: Google, PubMed, Taylor and Francis, Elsevier, Science Direct, and Scopus).

Fig. 1 Structure of voriconazole. 


\subsection{Effect of analytical methods on the environment}

Liquid chromatography and its related methods are widely used and accepted for the estimation of pharmaceutical substances. The mobile phase commonly employs components such as water, buffers, additives to adjust $\mathrm{pH}$, and organic modifiers like methanol $(\mathrm{MeOH})$ and acetonitrile $(\mathrm{ACN})$. These organic modifiers are mostly preferred for the LC method because of their ease of practical applicability as well as miscibility in water, low UV wavelength cut-off range (205 $\mathrm{nm}$ for $\mathrm{MeOH}$ and $190 \mathrm{~nm}$ for ACN), high purity, and low or no reactivity with most pharmaceutical substances. ${ }^{9,10}$ Despite the remarkable advantages of liquid chromatography, most reported solvents have a highly adverse environmental impact. ${ }^{\mathbf{1 1 , 1 2}}$ ACN causes adverse health effects since it is a systemic irritant, is flammable, toxic, and volatile, and is categorized as an occupational hazard for analysts due to risk of inhalation and skin/eye contact. Methanol's vapor pressure is low; thus, it can easily volatilize into the surrounding air. Methanol degrades through interaction with airborne hydroxyl radicals after volatilization, and its half-life is about 18 days. ${ }^{13}$ Organic solvents like $\mathrm{MeOH}$ and ACN that are frequently used in chromatographic analysis affect animals, birds, and fish, cause death, and affect biota fertility. These two solvents are also included in the EPA's (Environmental Protection Act) TRI (Toxicity Reactivity Ignitability) list as hazardous solvents.

RP-HPLC consists of a stationary phase (column) and mobile phase (solvents) with a flow rate of $0.8-1.5 \mathrm{~mL} \mathrm{~min}^{-1}$. On average, usage of HPLC on a single day with a $50: 50$ ratio of organic phase and buffer with $1 \mathrm{~mL} \mathrm{~min}^{-1}$ flow rate generates $1.5 \mathrm{~L} / 24 \mathrm{~h}(750 \mathrm{~mL}$ of organic waste and $750 \mathrm{~mL}$ of aqueous buffer waste containing toxic chemicals in a single working day). Developing an eco-friendly method by controlling the waste generated without affecting the method quality and performance for analyzing compounds in HPLC is a mammoth task. However, this problem can be reduced by applying green analytical principles in drug analysis. This particular review aims to summarize and examine various VOR estimation methodologies currently available using different instrumental methods along with the estimation of the degree of the greenness of the same.

Anastas ${ }^{\mathbf{1 4}}$ portrayed 12 green analytical chemistry principles from the general green chemistry principles to help analysts in developing an environmentally fit method that can be used in the long term without affecting the environment.

\subsection{Green analytical chemistry principles ${ }^{15-20}$}

Green analytical chemistry principles are derived from the modification of green chemistry principles. Each principle has its unique role in the development of an analytical method. However, it is impractical to apply all the principles, but the number of principles incorporated in the method development makes the output most eco-friendly. (1) The generation of hazardous waste in sampling can be reduced by eliminating large volume dilutions. (2) The direct sampling technique cannot be implemented to analyze all samples in liquid chromatography due to its limitation. Still, this principle can be satisfied by selecting other techniques like IR and FTIR to make the analysis eco-friendlier. (3) Green or biodegradable chemicals or solvents must be used instead of toxic chemicals in the environment, e.g., methanol; acetonitrile needs to be replaced by ethanol and propylene carbonate. (4) Renewable solvents like 1,1-diethoxyethane, isosorbide dimethyl ether, eucalyptol, rose oxide, $\gamma$-terpinene, and $\alpha$-pinene ${ }^{21}$ shall be replaced by the other toxic solvents for the analysis. (5) The waste generation in liquid chromatography (LC) techniques has a significant environmental impact and is inevitable. Instead, the generated waste can be recycled using different distillation processes. (6) Upgrading existing techniques by miniaturization, wherein a lab-on-a-chip miniature device is developed, is a sophisticated technique for analyzing compounds in a simple step. (7) The novel combination of molecular biology with microelectronics has resulted in the electronic detection of biomolecules through field-effect transistors (FETs) and lab-on-a-chip biosensors. ${ }^{22}$ (8) Multiple analytical techniques have to be applied for the new method development. (9) Energy consumption for analyzing a sample should be as less as possible to make the method greener; for example, the application of UPLC rather than HPLC uses less energy. (10) Derivatization is an extra step for analyzing a drug that should always be avoided in most cases but it is an inevitable step; then, the green reagents need to be utilized for this step e.g., nicotinic acid, hydrindantin dihydrate, ferrocene carboxaldehyde, and (+)-diacetyl-s-tartaric anhydride. (11) In situ measurements necessitate that equipment is placed directly at the site of analysis and in touch well with the subject of interest of the drug or sample. (12) Occupational hazards need to be nullified in consideration towards the analyst.

As it is mentioned early that application of all the principles in analytical methods is practically very difficult so some strategies have to be applied for developing the methods that should be environmentally safe.

\subsection{Strategies for greening an analytical process - solvent reduction $^{23-28}$}

Reduction of solvent consumption leads to the reduction of waste. There are numerous ways to reduce it. (i) Using RP-HPLC methods instead of the normal phase will allow for polar solvents that are non-hazardous. (ii) Short column usage will make the elution faster and reduce waste. (iii) Microflow and capillary HPLC columns will decrease the flow rates and reduce solvent consumption. (iv) Higher column temperature will decrease water viscosity and also enhances polar characteristic that reduces the use of organic modifiers. (v) Newer columns like fused core particle columns will have smaller particle sizes that makes the separation faster and better. (vi) Finally, miniaturization from HPLC to UPLC with short columns and high pressure makes the analysis faster and decreases the waste generated.

1.4.1. Solvent replacement. ${ }^{29-33}$ Flammable and toxic solvents can be replaced by bio solvents, as follows: (i) toxic solvents such as ACN, $\mathrm{MeOH}$, and ethyl acetate can be replaced by eco-friendly solvents such as propylene carbonate, ethanol, and ethyl lactate, respectively. These eco solvents have similar 
properties to the other solvents and are a perfect replacement. (ii) Superheated water at $80-250{ }^{\circ} \mathrm{C}$ can be an alternative in specific cases as water is inexpensive, non-flammable, ecofriendly and has a low UV cut-off wavelength. However, this has drawbacks, such as the fact that hydrophobic samples cannot be analyzed by simple water and thermolabile drugs cannot be determined at these high temperatures. (iii) Supercritical fluid can also be a better substitute as it provides higher separation and faster elution.

1.4.2. Sample preparation. ${ }^{34-38}$ Choosing a direct analytical method is not possible for analyzing all samples in LC. Instead, sample preparation can be done by (i) using eco-friendly solvents for preparation of samples by avoiding transportation and (ii) unavoidable extraction processes using toxic chemicals can be replaced by micro-wave assisted, ultrasound-assisted, and pressurized liquid extraction.

1.4.3. Analytical quality by design (AQbD). ${ }^{39-43}$ The QbD approach suggests looking into the quality of the analytical process during the development stage itself. It says that quality should be built into the process design rather than testing into results of the analytical process. When the QbD principles are applied in the method development of pharmaceutical substances, the strategy can be called analytical quality by design. The outcome of AQbD is well understood and fit for its intended purpose with sturdiness throughout the lifecycle.

\section{Evaluation of greenness}

A method should be carefully assessed before claiming the greenness of the technique. However, GAC's lack of dedicated evaluation tools has been considered the main problem in greenness estimation. Although different evaluation tools are available for green chemistry, all have their limitations in GAC. A few green assessment tools that can be applied in GAC are as follows.

\subsection{National environmental methods index (NEMI) ${ }^{44-48}$}

NEMI is considered as the oldest evaluation tool used to assess green chemistry and represent a quadratic pictogram. Each quadra represents one factor: persistent bioaccumulative and toxic (PBT), hazardous, corrosive, and waste. If a chemical is used in the method listed in the EPA (Environmental Protection Act) TRI (Toxicity Reactivity Ignitability) list, the quadra must be left blank. If not listed, it should be coded with green color. Solvents/chemicals, if listed in Resource Conservation and Recovery Act (RCRA), were used in the method, then the next quadrant should be left blank; if the chemicals used in the process are non-corrosive, then the next quadrant should be coded green; finally, if the waste produced by the method is more than $50 \mathrm{~g} \mathrm{~mL}^{-1}$ then the next quadrant has to be left blank.

\subsection{Green analytical procedure index (GAPI) ${ }^{49-54}$}

This evaluation system is also similar to NEMI, but it covers a few more aspects. The hazardous solvents need be to checked in the National Fire Protection Act (NFPA) instead of the EPA
TRI list for GAPI. The pictogram contains three colors: green, yellow, and red instead of green or none. Colour should be coded based on the solvents used, like highly toxic coded as red, moderately toxic as yellow, and less or non-toxic as green. Different parameters that need to be checked for the GAPI are sample preparation, preservation, transport, storage, type of method, the scale of extraction, solvents used, additional treatments, and amount of reagents used. Although it covers most aspects required to evaluate GAC, the output based on color representation makes this a qualitative rather than quantitative tool.

Płotka ${ }^{55}$ developed a new tool in 2021 named complementary GAPI or complex GAPI, which is an advancement of GAPI. This complex GAPI is a combination of classical GAPI and E-Factor, where E-Factor mainly focused on the synthesis of the chemicals along with the product yield, purity, waste, etc. Because the study design is solely concerned with the development of analytical methods and their greenness estimate, and there is no published literature on synthesis data of analyte and solvent, the implementation of the complex GAPI is minimal.

\subsection{Analytical eco-scale (AES) ${ }^{56,57}$}

Although eco-scale was first introduced to evaluate GC, it shows promising results when applied to GAC. When eco-scale is used for analytical methods, then it can be called AES. This tool has an output of numerical values as the eco-scale score equals ' 100 '. The deduction of the eco score is based on the penalty points (PP) scored by the method.

PP for reagents used:

- Less than $10 \mathrm{~g}$ or $\mathrm{mL}=1 \mathrm{PP}$.

- 10-100 g or $\mathrm{mL}=2 \mathrm{PP}$.

- More than $100 \mathrm{~g}$ or $\mathrm{mL}=3 \mathrm{PP}$.

PP based on chemicals used:

- Pictogram with danger representation $=2 \mathrm{PP}$.

- Pictogram with warning representation $=1 \mathrm{PP}$.

- No Pictogram representation $=0 \mathrm{PP}$.

PP based on energy used per sample.

- Less than or equal to $0.1 \mathrm{~kW} \mathrm{~h}=0 \mathrm{PP}$.

- Less than or equal to $1.5 \mathrm{~kW} \mathrm{~h}=1 \mathrm{PP}$.

- More than or equal to $1.5 \mathrm{~kW} \mathrm{~h}=2 \mathrm{PP}$.

PP based on waste generated.

- No waste = 0 PP.

- Less than $10 \mathrm{~g}$ or $\mathrm{mL}=1 \mathrm{PP}$.

- 1-10 g or $\mathrm{mL}=3 \mathrm{PP}$.

- More than $10 \mathrm{~g}$ or $\mathrm{mL}=5 \mathrm{PP}$.

The results of greenness from the eco scale.

- Eco score $\geq 75=$ worthy green method.

- Eco score $\geq 50$ = optimal green method.

- Eco score $<50=$ not a green method.

\subsection{Analytical GREEnness (AGREE) $)^{58,59}$}

It is a software-based assessment tool covering all the 12 principles of GAC. It works based on graphical user interface (GUI) technology. It gives a result in numerical values with a high of 1 showing complete green, whereas the decrease in the number indicates a reduction in greenness. It contains 12 steps as the 
sampling procedure, sample size, in situ measurement, steps in the process, miniaturization, derivatization, waste, number of analytes, energy, type of reagents, toxic reagents, and operator safety need to be filled in software for obtaining the green results. The score of 1 indicates a complete green method, and the result near 1 indicates that the process was obeying the ecofriendly conditions and vice versa.

\subsection{Analytical method greenness score (AMGS) ${ }^{60-62}$}

AMGS is a spreadsheet calculator dedicated to the chromatographic method of analysis. It is an amalgamation of HPLCenvironmental assessment tool cumulative energy demand (CED) for instrument and solvent selection, analytical mass volume intensity (AMVI) for assessing solvent wastage, and safety, health, and environmental assessment (SHE) for determining solvent safety through geometric mean. The present spreadsheet works by having the data of the method and executing it for the evaluation; the output value should be as low as possible to obtain the greenest of the results.

\subsection{Carbon footprint}

Carbon footprint is an important concept for calculating the emission of global warming gases into the atmosphere generated during any fossil fuel combustion. It is important to calculate the carbon footprint for an industry in a whole process to understand the overall emission of greenhouse gasses into the atmosphere. The present study deals with the analysis of voriconazole using different analytical instruments, as this equipment utilizes significantly fewer energies for the determination of single samples (HPLC consumes $\geq 1.5 \mathrm{~kW} \mathrm{~h}$, UPLC and UV-VIS spectrophotometry absorbs $<1.5 \mathrm{~kW} \mathrm{~h}$, and LCMS utilizes $>1.5 \mathrm{~kW} \mathrm{~h}$ ). This energy consumption generates significantly less $\mathrm{CO}_{2}$, which produces negligible effects on the environment. This energy measurement was incorporated into a few greenness assessment metrics like GAPI, AES, and AGREE, which nullifies the complexity of the carbon footprint analysis regarding energy consumption.

The above assessment tools have been utilized to demonstrate the greenness in reported methods for the analysis of VOR to scrutinize and select the best approach in terms of ecofriendliness. Although each greenness assessment tool utilizes a different way of analyzing the greenness profile, the final results help to picturize and identify the more environmentally benign method with its environmental impact. Here, four assessment tools were used for assessing the greenness of the reported methods.

\section{Methods for the quantification of VOR and its combinations}

\subsection{Official methods}

VOR was added to the pharmacopeias such as the United States Pharmacopeia (USP), British Pharmacopeia (BP), and Indian Pharmacopeia (IP) officially ${ }^{63-65}$ in 2018 after 16 years of approval from the FDA. All these methods have used liquid chromatography as a technique for the analysis of VOR.

\subsection{United States Pharmacopeia, British Pharmacopoeia, and Indian Pharmacopoeia}

The major official pharmacopeias state that the method for the analysis of VOR was HPLC using an L1 packing column with end-capped octadecyl silyl silica gel $(150 \mathrm{~mm} \times 3.9 \mathrm{~mm}, 4 \mu \mathrm{m})$, with a mobile phase consisting of $\mathrm{ACN}: \mathrm{MeOH}:$ ammonium formate ( $\mathrm{pH} 4.0$ ) in a ratio of $15: 30: 55 \mathrm{v} / \mathrm{v} / \mathrm{v}$ at a flow rate of 1.0 $\mathrm{mL} \min ^{-1}$ determined in a wavelength of $256 \mathrm{~nm}$ with a retention time of $8 \mathrm{~min}$ for VOR. The acceptance criterion according to USP, BP, and IP for VOR was 97.5-102.0\%. The greenness assessment for the official method was performed using the NEMI, GAPI, AES, and AGREE assessment tools for the pharmacopeia data and is depicted in Fig. 4.

\section{3. $\quad$ Reported methods}

Articles were collected for VOR in pharmaceutical dosage forms from Science Direct, PubMed, Scopus, Taylor and Frances, Google, and different web sources from 1997 to 2021 and were organized and executed for the present review.

3.3.1. UV-VIS spectrophotometry. Spectroscopic methods like UV-VIS play a significant role in the quantification and qualification of most of the drugs. UV-VIS is essential in all quality control departments to make the analysis of drugs accurate and simple. It is also combined with modern analytical techniques like HPLC to give more accurate results. The determination of VOR by UV has used $\mathrm{MeOH},{ }^{\mathbf{6 6}, 67}$ water, ${ }^{68} \mathrm{HCL},{ }^{69}$ and phosphate buffer ${ }^{70}$ in a wavelength range around 252-256. The visible range for the derivatization chemicals/solvents like tropaeoline ooo and azocarmine-G was used at a wavelength of 500 and $550 \mathrm{~nm}$. The overall spectrophotometric methods reported for VOR analysis and the results of the assessment of greenness by applying four tools are depicted in Table 1 .

3.3.2. High-pressure liquid chromatography. HPLC is a critical and widely used analytical method for quantifying the majority of pharmaceutical dosage forms. Additionally, HPLC is a very trustworthy technique for measurement due to its precision, robustness, and sensitivity. Estimating VOR has utilized a set of different mobile phase combinations with a common organic phase like $\mathrm{MeOH}$ and $\mathrm{ACN}$ and various phosphate buffers. Initial development results showed the longest retention time of 21.06, but technology improvisation leads to the shortest elution of analytes at $3.02 \mathrm{~min} .{ }^{72}$ Although the linearity selected in the reported HPLC methods did not
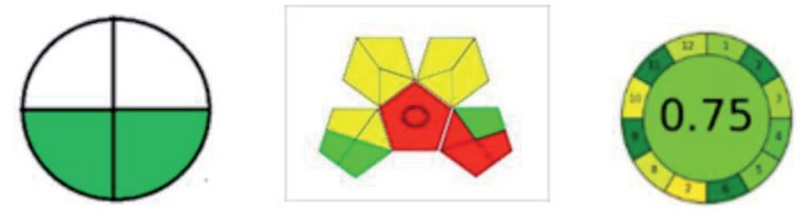

$$
\begin{gathered}
\text { AES }=11+1+3+3=18 \\
\Sigma=82
\end{gathered}
$$

Fig. 4 NEMI, GAPI, AES, and AGREE assessments for the official methods. 


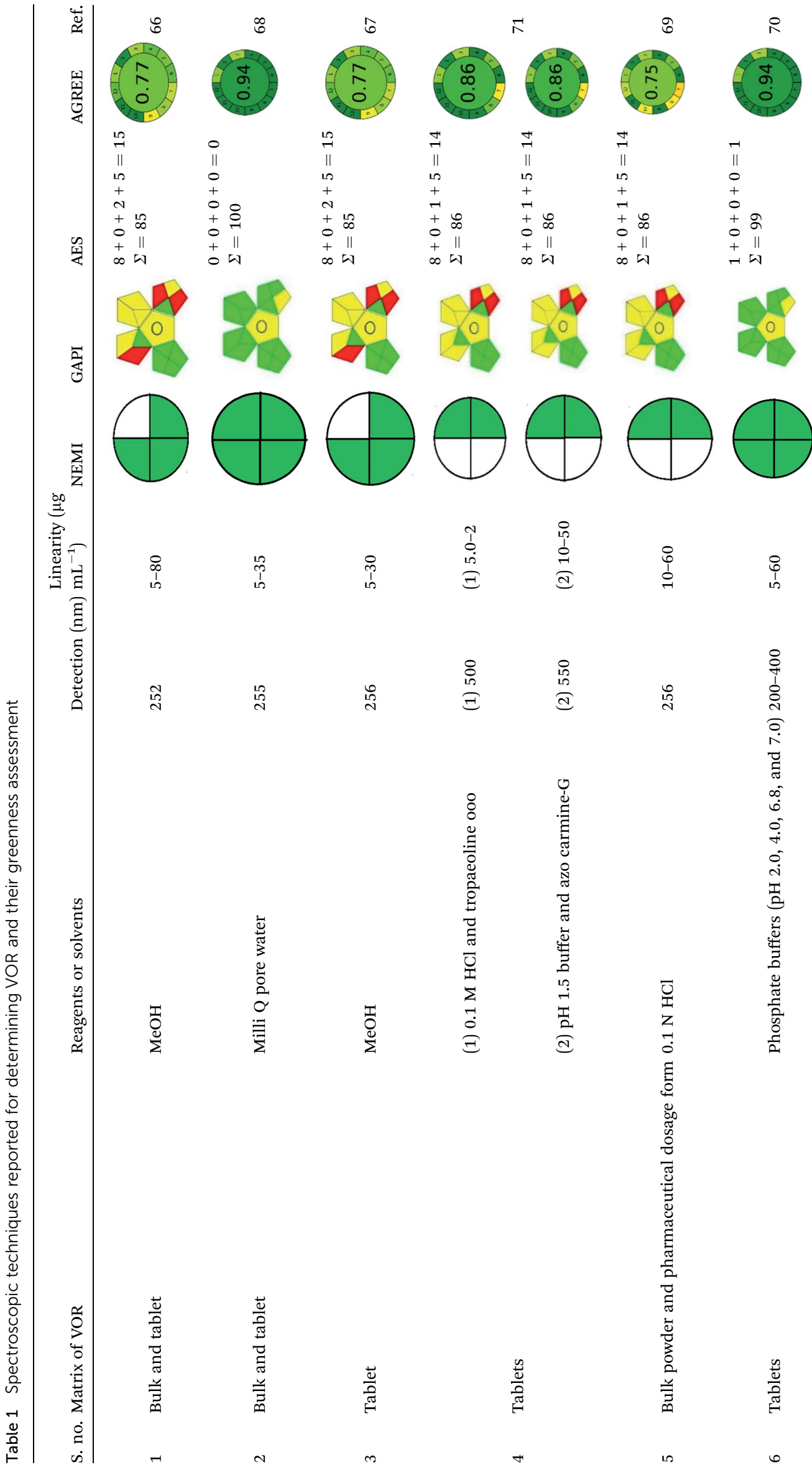




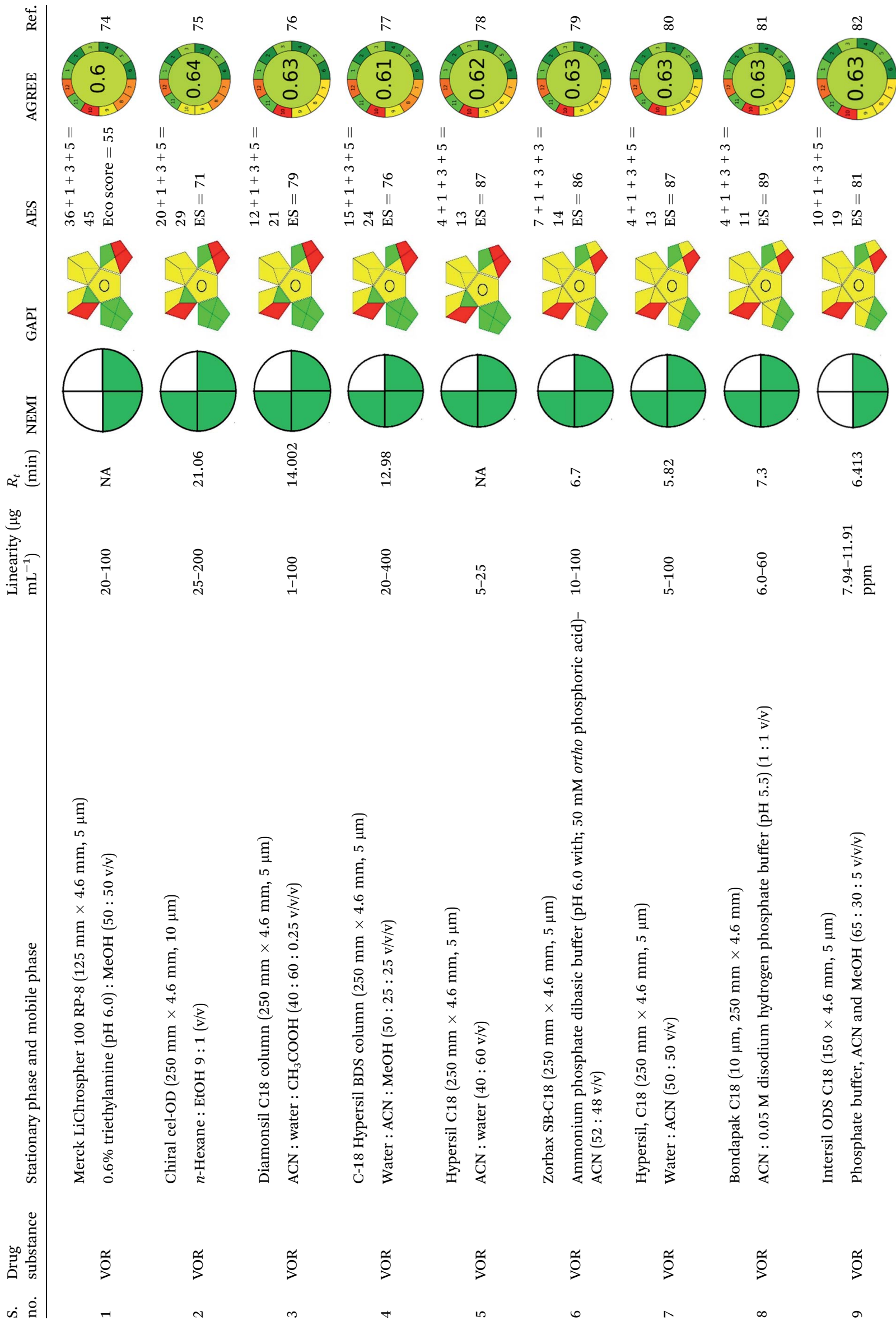



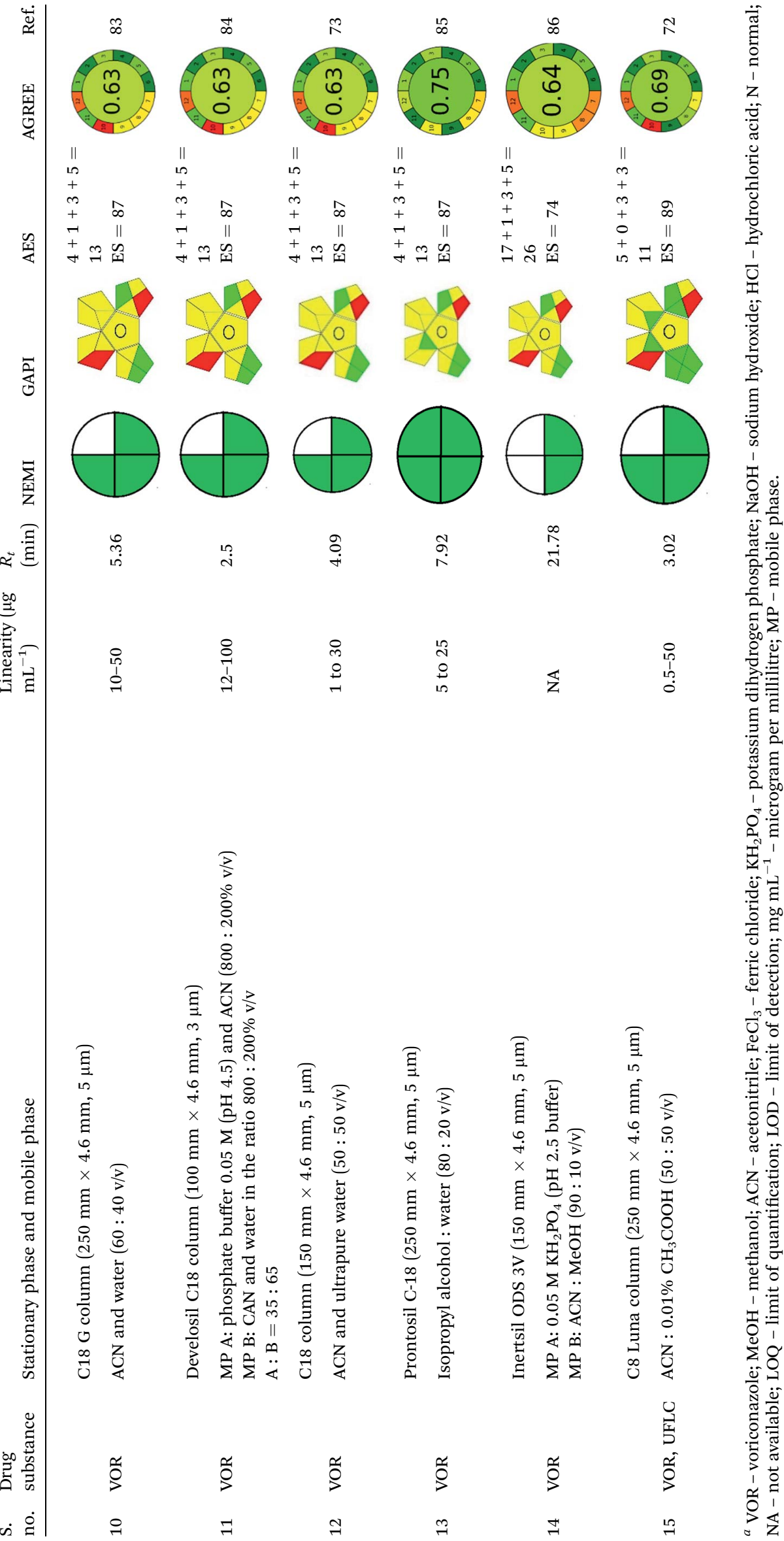
broadly vary from the corresponding procedures, the chosen narrow range among the methods was 1 to $30 .^{73}$ Detectors like UV and photo diode array (PDA) were considered as another important factor for more accurate analysis of drugs with the reported methods of RP-HPLC. Among the two detectors PDA was selected by most of the methods due to their advantages like fast and more sensitive detection at multiple wavelengths. Table 2 summarizes the RP-HPLC techniques reported for the VOR study in single and combination dosage forms along with the application of four green assessment tools.

3.3.3. High-performance thin layer chromatography (HPTLC). HPTLC is a quick, dependable, and accurate qualitative and quantitative drug analysis; it is a viable alternative method for drug testing. Unfortunately, there are just a few HPTLC techniques available for determining VOR alone or in combination.

Khetre et $a{ }^{87}$ utilized HPTLC to develop a technique for detecting VOR in human plasma in API and therapeutic dosage forms. This technique used silica-gel 60 F254 precoated on aluminum sheets as the stationary phase and mobile phase comprising $\mathrm{MeOH}$ : toluene ( $7: 3 \mathrm{v} / \mathrm{v}$ ), and VOR is quantified at $255 \mathrm{~nm}$ using densitometric analysis. VOR's $R_{\mathrm{f}}$ values were determined to be $0.58 \pm 0.02$. The linear connection between the 200-1000 ng per spot concentration range showed an excellent linear regression. The detection and quantification limits were 12.05 and $36.55 \mathrm{ng}$ per spot, correspondingly. This study showed a superb quantification value when compared to the other methods.

Similarly, Dewani et al. ${ }^{88}$ developed an HPTLC method to determine VOR in human plasma using the mobile phase combination of triethylamine : $\mathrm{MeOH}$ : toluene in the proportion of $0.1: 4: 6 \mathrm{v} / \mathrm{v} / \mathrm{v}$, in silica gel $60 \mathrm{~F} 254$ as a stationary phase. The sample was prepared by dissolving plasma protein precipitation using ACN solvent. The analysis of the VOR has been performed at a wavelength of $254 \mathrm{~nm}$ in the concentration range between 50 and $400 \mathrm{ng}$ per band, which exhibits a good range of linearity. The mean rate of drug recovery was determined to be $98.82 \%$ for VOR using the reported method.

In another study, Jain et al. ${ }^{89}$ quantified VOR in raw materials and cream formulations using the stationary phase of aluminum plates coated using silica-gel $60 \mathrm{RP}-18 \mathrm{~F}-254 \mathrm{~S}$ and mobile phase with a mix of ACN : water $(60: 40 \mathrm{v} / \mathrm{v})$. Under a 200 to $1200 \mathrm{ng}$ per band concentration, the absorbance of $257 \mathrm{~nm}$ was calculated with an $R_{\mathrm{f}}$ of $0.48 \pm 0.02$. The $R^{2}$ value is 0.999 , indicating a strong linear correlation. The levels of detection and quantification are $19.99 \mathrm{ng}$ and $60.60 \mathrm{ng}$, correspondingly. This method helps to identify the VOR in the cream formulation and makes the analysis simplified.

Also, Santosh V. et al. ${ }^{90}$ established a method for estimating VOR in pharmaceutical dosage form with a chromatographic separation on precoated aluminum plates using silica gel 60 F254 and mobile phase composed of $\mathrm{MeOH}$ : toluene $(2: 8 \mathrm{v} / \mathrm{v})$, tracked at $256 \mathrm{~nm}$ by densitometric scanning. The $R_{\mathrm{f}}$ value of VOR was at $0.45 \pm 0.02$. The linear range was found to be $400-$ $1600 \mathrm{ng}$ per band. The quantitation and detection limits for VOR were identified to be 61.30 and $20.22 \mathrm{ng}$ per band, correspondingly. The overall assessment of the available reported HPTLC methods is depicted in Table 3.

3.3.4. Bioanalytical methods. Bioanalysis is a critical component of the pharmacokinetic/pharmacodynamic evaluation of a new drug entity, beginning with its discovery and continuing through various stages of drug development and approval. This compilation discusses critical bioanalytical characteristics and their implementation to drug discovery methodologies, which will aid in the production of safer and more effective medications with less time and expense. It is

Table 3 Green assessment for the reported HPTLC methods

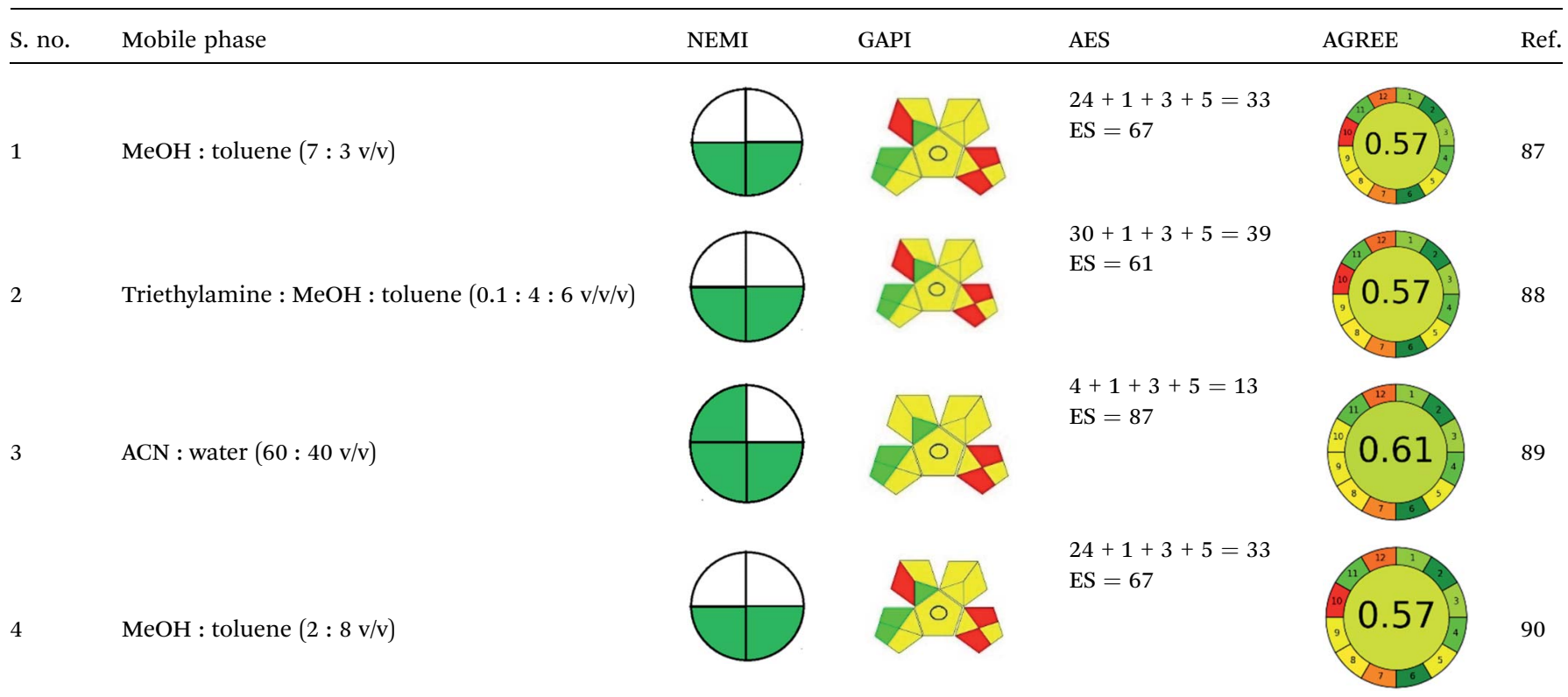




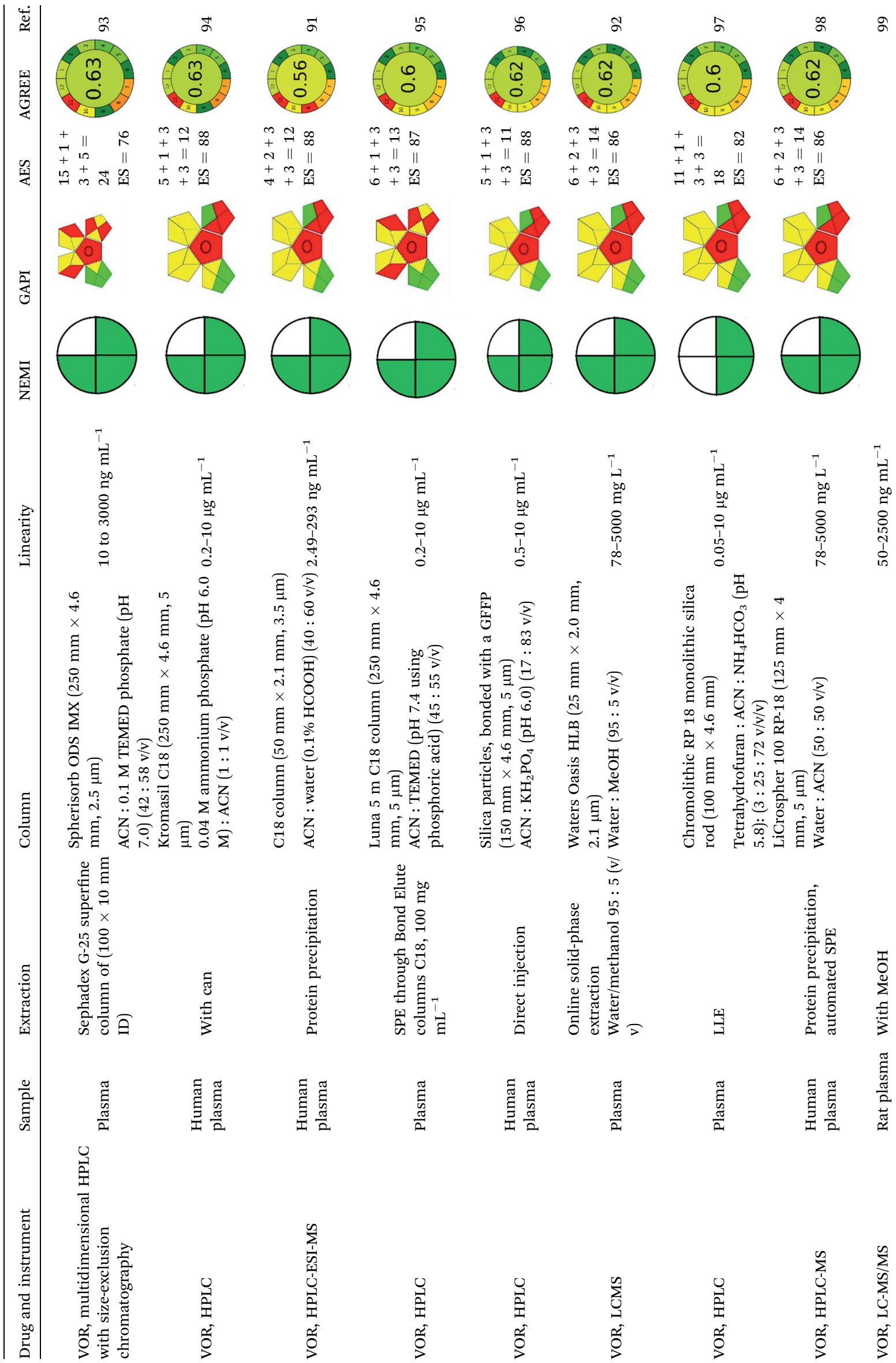




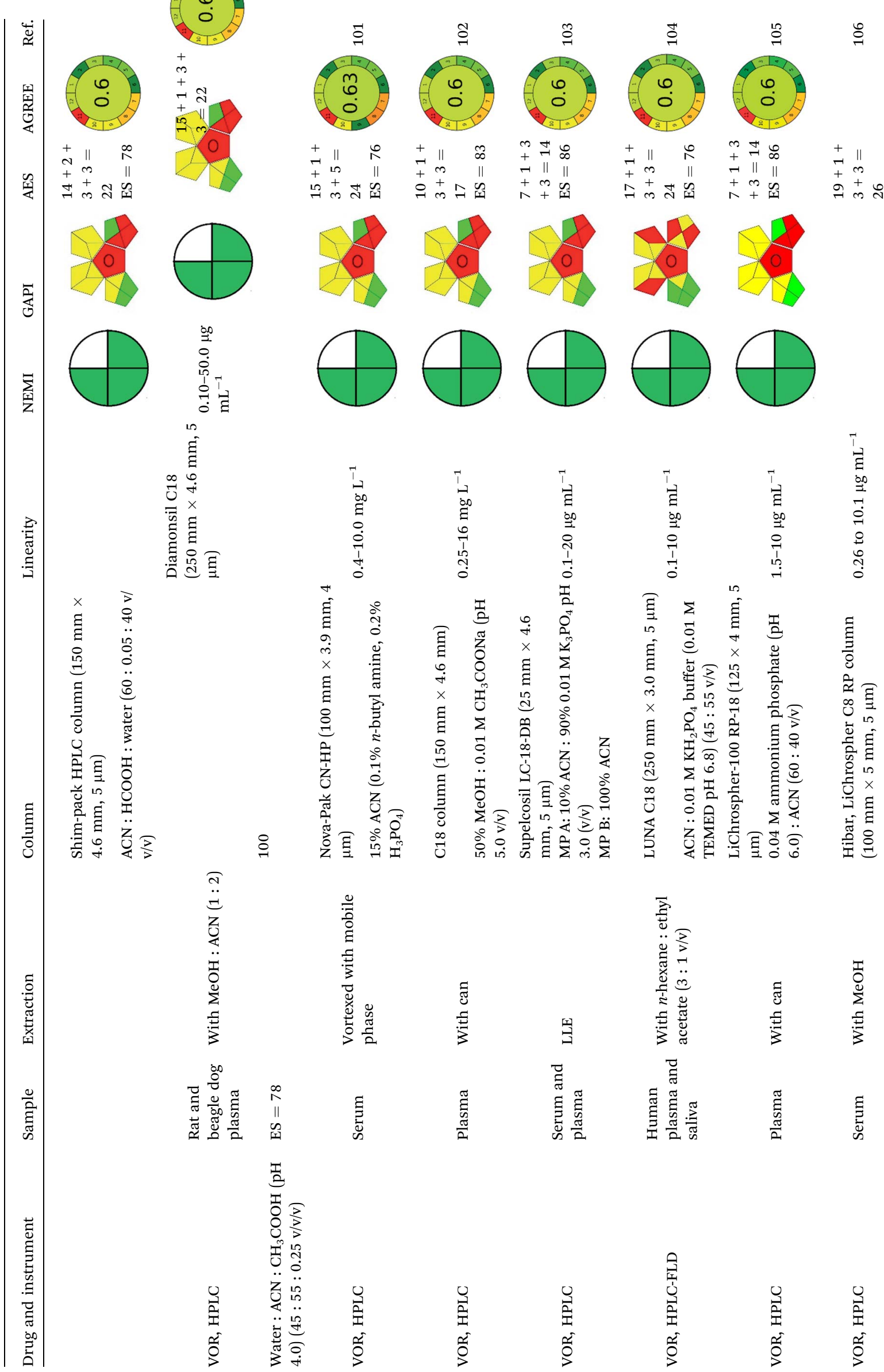




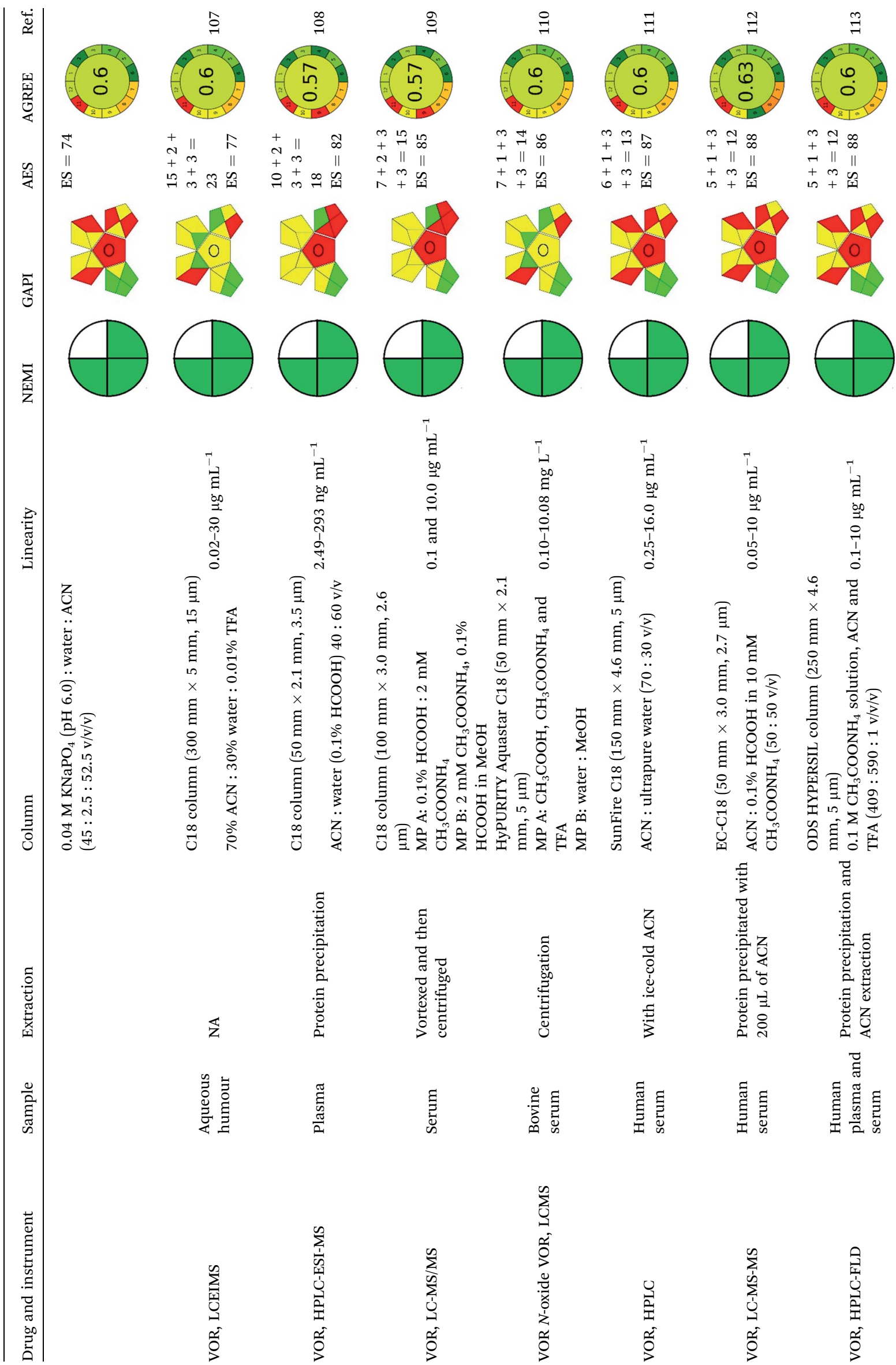



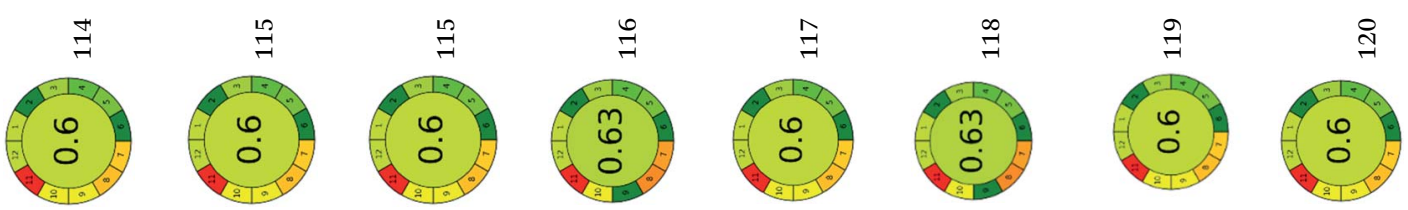

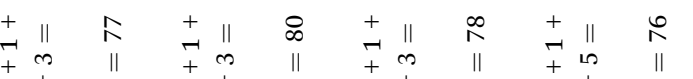

$\infty$
$+\neq$
711
+

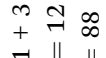

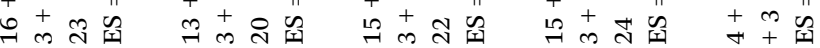

$+\pi=$

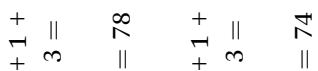
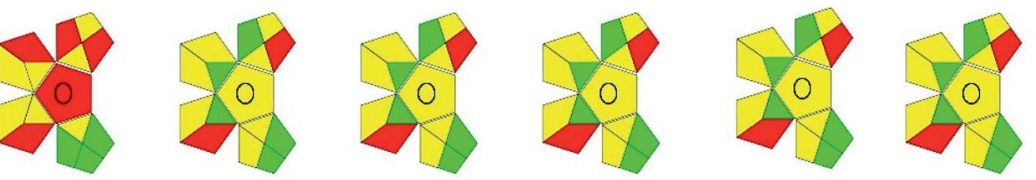

in + ind

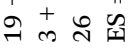

\section{疍}
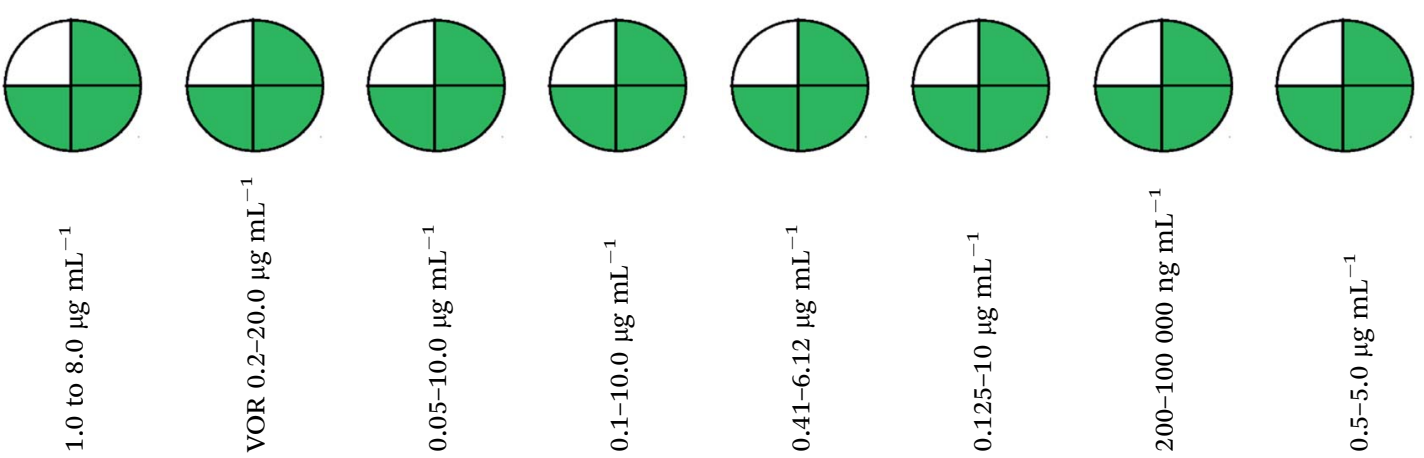

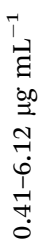

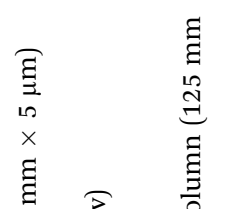

贾要㤎

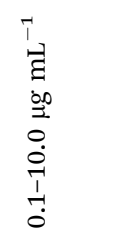

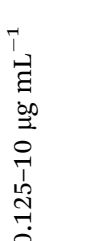

1
$\Xi$
8
$\vdots$
8
8
8
8
1
8

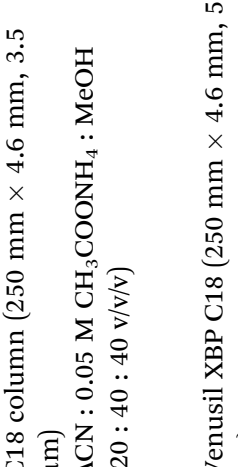

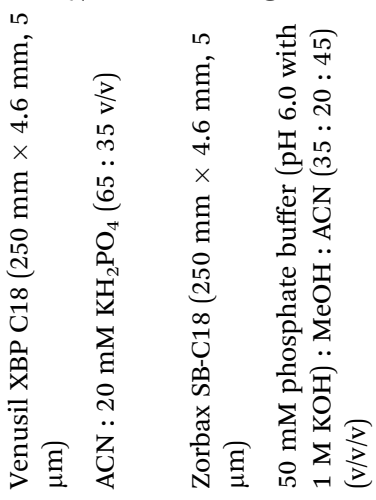

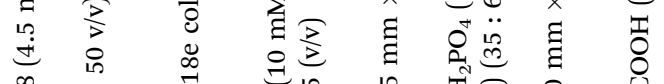

盛

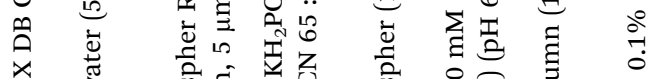

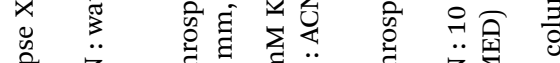

垔

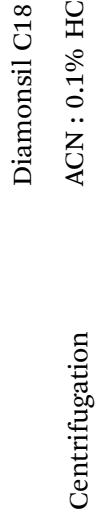

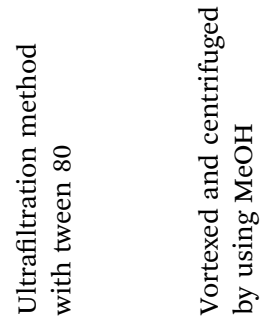

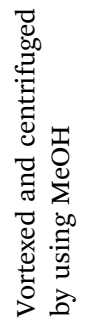

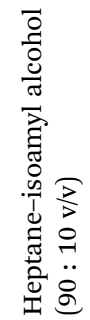

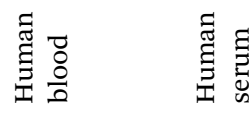

$\frac{\pi}{\pi}$

萦

$\frac{\widetilde{m}}{\frac{\pi}{2}}$

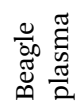

密苛

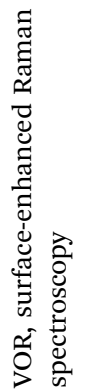

彞

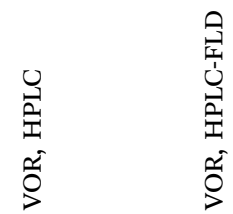

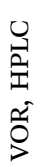

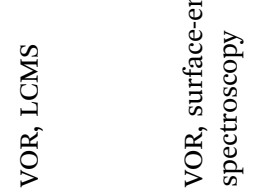

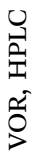

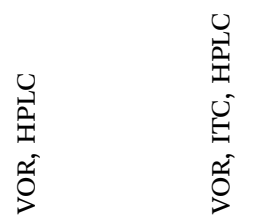




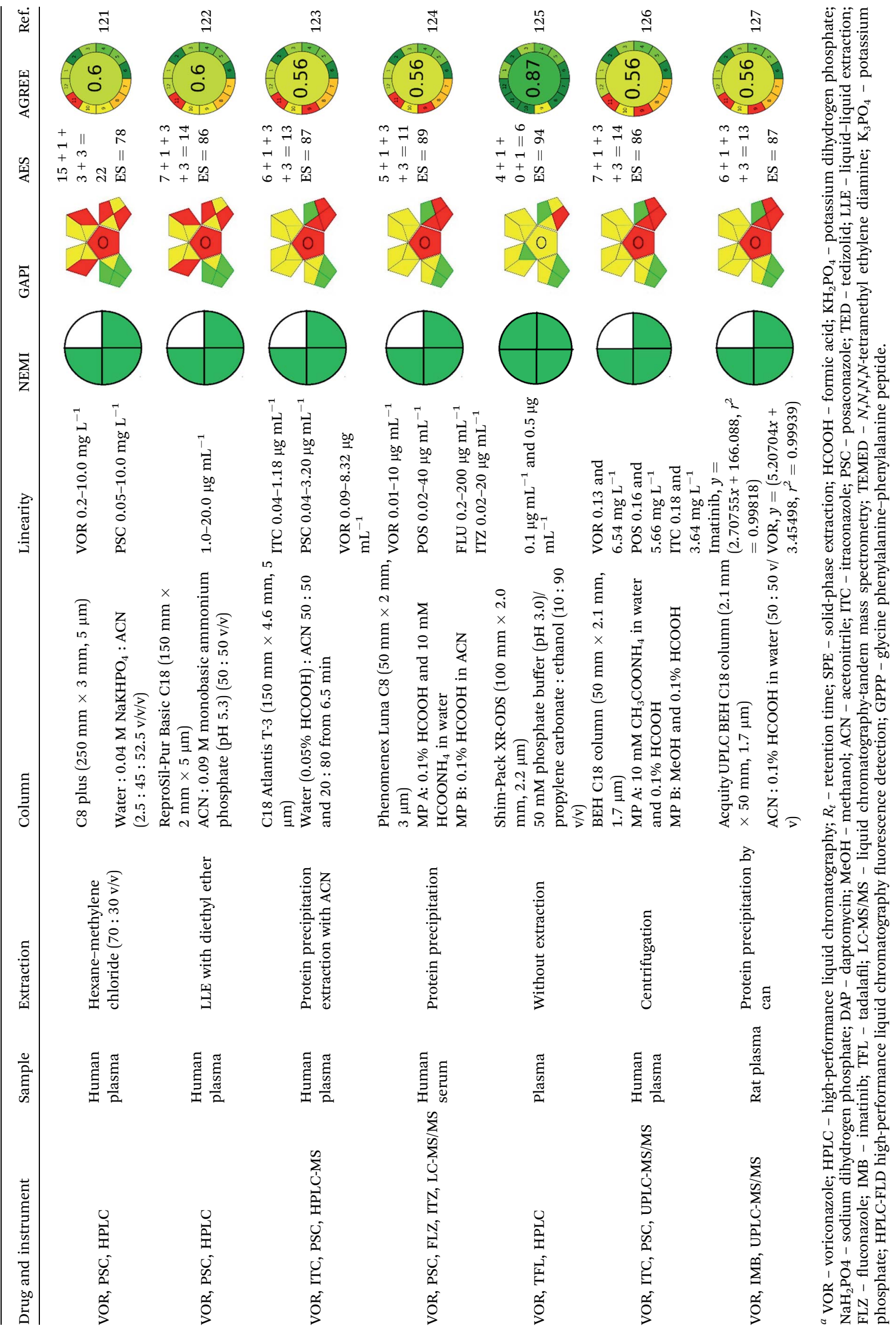


aimed to provide some broad views in this field that will serve as the foundation for a general framework for approaching bioanalysis from the start (i.e., identification of a pioneer chemical) to the different stages of the development process. VOR estimated in various biological matrixes like blood (human), plasma (human, rat, dog, and beagle), serum (human and rat), and aqueous humour (human). Solvent systems like ACN, $\mathrm{MeOH}$, hexane, ethyl acetate, heptane, isoamyl alcohol, hexane, methylene chloride, and diethyl ether were used in different reported methods for the efficient extraction of VOR from various biological matrixes. The minimum linearity concentration reported was $2.49 \mathrm{ng} \mathrm{mL}^{-1}$ (ref. 91) to the maximum of $5000 \mathrm{mg} \mathrm{L}^{-1}$ (ref. 92). The detection of VOR in biological matrices used different detectors like PDA, UV, fluorescence detection, surface-enhanced Raman spectroscopy, mass spectrometry (MS) and MS/MS. Although each detector has its own advantages, mass spectrometry was the predominantly utilized detector, which has a great potential of more accurate detection even at very low concentration. This also forces the methods to select volatile buffers like formic acid and acetic acid for better compatibility with the organic phase of $\mathrm{MeOH}$ and ACN. The bioanalytical techniques for measuring VOR alone and in combination with other medications, along with their greenness assessment, are summarized in Table 4.

3.3.5. Miscellaneous methods. A chromatographic method was proposed by Babu et al. ${ }^{128}$ for analyzing VOR in pharmaceutical formulations using a quality by design approach. The stationary phase utilized for the method was the C18 column $(250 \mathrm{~mm} \times 4.6 \mathrm{~mm}, 5 \mu \mathrm{m})$, and a $50: 50 \mathrm{v} / \mathrm{v}$ blend of ACN and

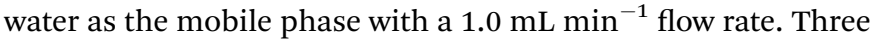
variables were taken into account while determining robustness, which were the proportion of ACN in the mobile phase, the $\mathrm{pH}$, and the flow rate; a rising inflow leads to a reduction in the concentration of the drug detection, while the proportion of $\mathrm{ACN}$ and the $\mathrm{pH}$ had significantly less impact on the response. A correlation coefficient of 0.9999 was determined to prove the noteworthiness of the developed method. The RSD result $(0.45 \%, n=24)$ showed that the analytical technique is precise and accurate and shall be used for long-term use due to applying the analytical quality by design concept.

In another study, Lin et al. ${ }^{129}$ established a technique for determining VOR concentrations in a patient's plasma sample using sweeping-micellar electrokinetic chromatography on a fused silica capillary of $75 \mathrm{~cm} \times 50 \mathrm{~mm}$ ID column. The solution included $110 \mathrm{mM}$ sodium dodecyl sulfate, $20 \% \mathrm{ACN}$, and $40 \mathrm{mM}$ phosphoric acid. The voltage applied was $-23 \mathrm{kV}$, and the wavelength of detection was $254 \mathrm{~nm}$. VOR was isolated from endogenous materials within 10.5 min under optimum analytical conditions, limiting the detection at $0.075 \mathrm{~g} \mathrm{~mL}{ }^{-1}$. Plasma VOR levels were quantified in 16 individuals; the findings were consistent with those acquired by the HPLC method. This method may be recognized as a new technique by applying a new concept called sweeping-micellar electrokinetic chromatography. Still, this technique was eventually used to develop a green analytical method. In this technique, the authors used ACN as an organic modifier, making this method vulnerable towards eco-friendly usage. However, these types of methods are encouraged and need to be optimized by applying some biodegradable solvents.

Similarly, Corbini et al. ${ }^{\mathbf{1 3 0}}$ devised a new technique for quantifying VOR using differential pulse polarography (DPP) in pharmaceuticals. A distinct peak $(-1.01 \mathrm{~V}$ versus $\mathrm{Ag} / \mathrm{AgCl})$ was produced using a $0.01 \mathrm{M} \mathrm{KH}_{2} \mathrm{PO}_{4}$ buffer ( $\mathrm{pH}$ 4.5) supporting electrolyte. Accordingly, the concentration stood linear in the series of 0.5 to $5.0 \mu \mathrm{g} \mathrm{mL} \mathrm{m}^{-1}$, through a LOD and LOQ of 0.03 and $0.10 \mu \mathrm{g} \mathrm{mL}^{-1}$. This resultant method consumes fewer toxic substances and may be used for sustainable development.

Smith et al. ${ }^{131}$ developed a GCMS method to determine VOR in serum. The sample extraction was performed with the help of cold methanol and ethyl acetate by adding the internal standard THC-deuterium 9 (THC-d9) and derivatized using N,O-bis(trimethylsilyl)trifluoro acetamide (BSTFA). The run time used for every run was about $11 \mathrm{~min}$ with a linearity range of 0.4 to 10 $\mu \mathrm{g} \mathrm{mL} \mathrm{L}^{-1}$. This method showed a better result with no interaction with the other drugs. It was the best adaptable one for VOR analysis in the serum without interference from the other substances.

Recently, Lerch et $a .^{132}$ developed a rapid and efficient analytical technique called paper spray mass spectrometry (PSMS), used for the first time to quantify VOR in the complex biological matrix without using chromatographic or traditional sample separation. An innovative PSMS technique for quantitating VOR in equine tears has been determined and corroborated over a series of 10 to $1000 \mathrm{ng} \mathrm{mL} \mathrm{m}^{-1}$. The method demonstrates excellent accuracy, linearity $\left(r^{2}>0.990\right)$, inter and intra-day precision, and selectivity for the quantitation limit in equine tears. VOR was computed using three products compared to an internal standard with an isotope label, voriconazole-d3, with a $250 \mathrm{ng} \mathrm{mL}^{-1}$ standard concentration in samples. The authors further applied this technique to the analysis of 126 test samples, and acquired the sample dilution's integrity, and carryover impact was further examined and determined within acceptable limits.

In another study, Sahitya et al. ${ }^{\mathbf{1 3 3}}$ used Candida albicans as the test microorganism to develop a novel microbiological technique for examining VOR tablets. It was necessary to experiment with different mediums, species, and circumstances to optimize the diffusion test. During a prospective validation, the method showed excellent linearity (0.995), accuracy less than $2 \% \mathrm{RSD}$, and consistency (mean recovery = $101.77 \%$ ). VOR was evaluated using HPLC, which was used as a comparative method for the study. The results of both the microbiological and HPLC techniques have been compared using the Student's $t$-test. The VOR content measured from both ways has demonstrated a high degree of consistency. When employed in dosage forms for regular quality control analysis of VOR, the newly developed microbiological analytical technique gives a genuine indicator of biological activity. It may be utilized to detect actual biological activity.

Kaur et $a l .{ }^{\mathbf{1 3 4}}$ recently devised and evaluated an RP-HPLC technique for determining VOR using an AQbD approach. The authors used a Taguchi design to address specific constraints that affect factors, including theoretical plate count, retention time, peak area, and peak tailing. Response 
Table 5 Green assessment for the reported miscellaneous methods

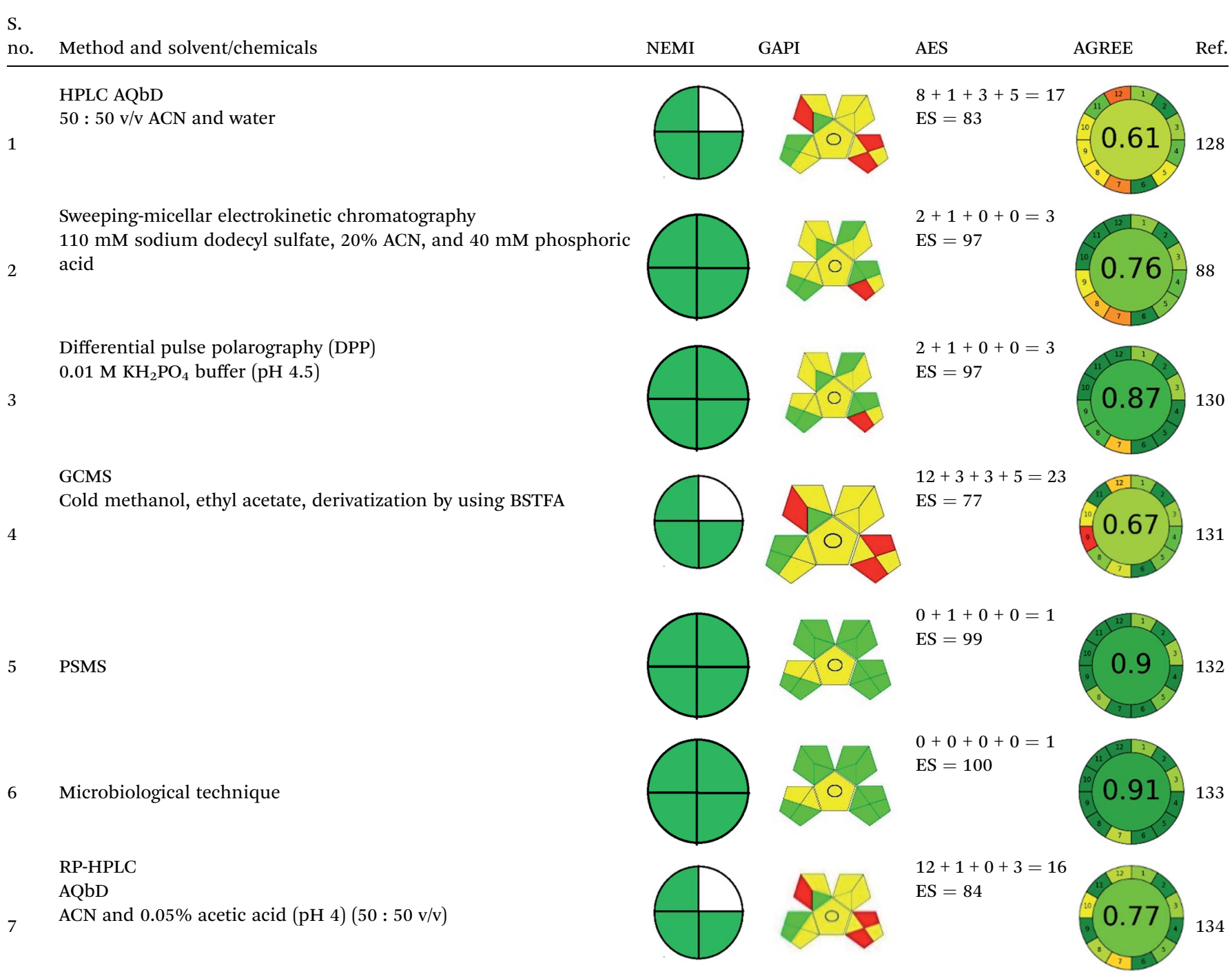

Sweeping-micellar electrokinetic chromatography $110 \mathrm{mM}$ sodium dodecyl sulfate, $20 \% \mathrm{ACN}$, and $40 \mathrm{mM}$ phosphoric

Differential pulse polarography (DPP)

GCMS

\section{4}

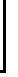

surface design is used for optimization studies to identify critical constraints such as organic phase mix in the mobile phase and flow rate that affect variables such as peak tailing, theoretical plates, peak area, and retention time by a central composite design. The optimum operating conditions for the technique were determined using graphical refinement and then verified by Monte Carlo simulations. The optimum mobile phase condition was ACN and $0.05 \%$ acetic acid $(\mathrm{pH} 4)$

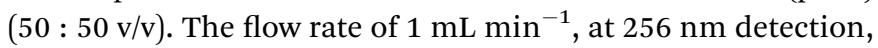
demonstrated linearity within $0.1-50 \mu \mathrm{g} \mathrm{mL}^{-1}$ in Hanks balanced salt solution and methanol. Corroboration data showed the proposed analytical method's efficacy and sensitivity in quantifying VOR. Quantification of VOR in pharmaceutical nano-formulations was effectively accomplished using the established analytical technique. The above-mentioned miscellaneous methods were assessed using the four green assessment tools and are depicted in Table 5 .

\section{Discussion}

The present review compiles the analytical methods available for VOR estimation by spectroscopic, chromatographic, bioanalytical, and other techniques. The UV spectroscopic method mostly uses solvents like $\mathrm{MeOH}$, water, $\mathrm{HCl}$, and $\mathrm{NaOH}$ with a wavelength range of 252 to $256 \mathrm{~nm}$, which shows that the method is effortless to use and accurate. The most eco-friendly approach was the one reported by Roy S. et al. ${ }^{68}$ This method utilized only water as a solvent for the analysis, making the technique more environmentally benign. Derivatization or photometric methods use different chemicals like tropaeoline ooo. Azo carmine-G has no serious toxic indication reported by any manufacturers in their data safety sheet, which shows that these chemicals shall be considered eco-friendly and can be used to determine other drugs. Assessment results also show that the method was eco-friendly related to the chemicals, but 
the number of steps involved in this method reduced the score towards its environmental friendliness.

The HPLC methods utilized different solvents for the analysis of VOR in pharmaceutical substances. The eco-friendly method among the reported methods was Singh et al. ${ }^{85}$ In this, isopropyl alcohol and water was used as the mobile phase, which makes the process justifiable from an environmental standpoint. An approach can be picked based on the $R_{t}$ as well. A method was developed by Lingamaneni K. et al. ${ }^{72}$ with an $R_{t}$ of 3.02, which utilized less solvent compared to the other methods. The solvents used by the various reported methods in performing HPLC are depicted in Fig. 5. This indicates that most reported studies have utilized ACN and $\mathrm{MeOH}$ as solvents by changing the buffers at various $\mathrm{pH}$ levels. Among the fifteen reported methods four ${ }^{73,78,80,83}$ authors has employed the same mobile phase components, which showed the same green assessment results by changing the ACN : water composition. Adams et al. ${ }^{74}$ have used a mobile phase containing $\mathrm{MeOH}$ and triethylamine (TEA), in which TEA is considered toxic to human health and the environment as this reagent contains three pictograms indicating danger and has an NFPA score with three in both health and flammability, which leads to a decrease in the eco-score when applying the assessment tools. Nagarjuna et $a l .{ }^{75}$ reported a method using ethanol and $n$-hexane as a mobile phase. Despite ethanol being considered an ecofriendly solvent, incorporating $n$-hexane made the method lose its environmental friendliness, as $n$-hexane contains four pictograms indicating danger. Both Huang et al. and Lingamaneni et al. ${ }^{72,76}$ have used a similar mobile phase composed of ACN and acetic acid. Still, variation in the assessment results was observed due to the run time and elution of the compound. As discussed earlier, the Lingamaneni et al. method had a better greenness profile than the other methods due to their run time. The remaining methods have utilized a common organic solvent such as ACN and $\mathrm{MeOH}$ along with a solid buffer. The different buffers used for the reported methods were phosphate with the corresponding salts of ammonium, ${ }^{79}$ sodium,,${ }^{81,82,84}$ and potassium, ${ }^{86}$ which produced similar results in the greenness assessment.

Analysis of VOR and its combinations in biological fluids shows the importance of the drug and the need to develop an

\section{No. of articles for HPLC methods}
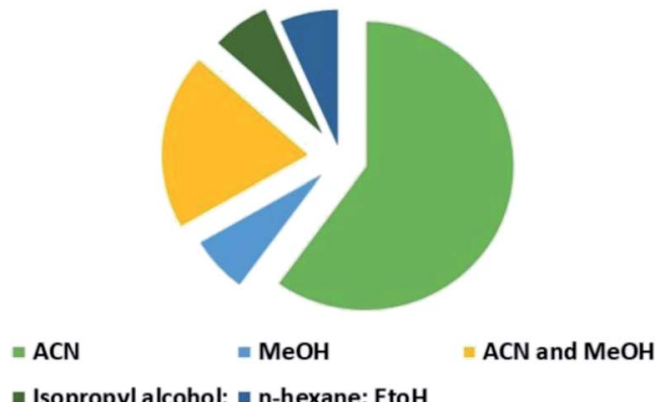

Fig. 5 Organic modifiers used by reported methods in analyzing VOR in HPLC. eco-friendly method without compromising the method quality as a better alternative to the reported approaches. The reported methods used several extraction techniques to separate VOR and its combinations such as biological matrix-like liquidliquid extraction (LLE), protein precipitation, centrifugation, vortexing, simple mixing with the solvent, and direct injection. Among these extraction methods, direct injection and green extraction may help the technique be more environmentally sound and eco-friendlier. In the analysis of bioanalytical samples, the most preferred organic phase was again $\mathrm{MeOH}$, $\mathrm{ACN}$, and an appropriate buffer. The selection of the organic phase and the corresponding number of times it appears in the reported methods are shown in Fig. 6. According to this, ACN is considered as the predominant solvent used in most of the available methods, followed by $\mathrm{MeOH}$. The present assessment tools showed that most methods had a similar greenness because the mobile phase selection was very similar with very slight variation.

Apart from the spectroscopy and chromatography methods, few reported methods explore the analysis of the drugs by applying the AQbD method for producing a long-term method, few other methods like sweeping-micellar electrokinetic chromatography, differential pulse polarography, paper spray mass spectrometry, and microbiological technique for the analysis of the VOR. The minimum linearity concentration reported was $2.49 \mathrm{ng} \mathrm{mL} \mathrm{m}^{-1}$ to the maximum of $100 \mu \mathrm{g} \mathrm{mL}{ }^{-1}$.

The greenness was further analyzed using NEMI, GAPI, analytical eco-scale, and AGREE metrics for all reported methods, and the results are shown in Tables 1-5. As explained earlier, each tool used in assessing greenness follows a different method for performing the greenness assessment. Considering the reported methods, ACN is used to a greater extent than $\mathrm{MeOH}$. Even though $\mathrm{MeOH}$ is less toxic when compared to ACN, only a few LC methods have been reported with $\mathrm{MeOH}$ and buffer as the mobile phase. Most methods mentioned using ACN as an organic modifier and other buffers show a repetitive technique that could be avoided. A green LC method has been reported to estimate VOR with the aid of eco-friendly solvents like propylene carbonate and ethanol and buffer with suitable method performance characteristics. There are very few green

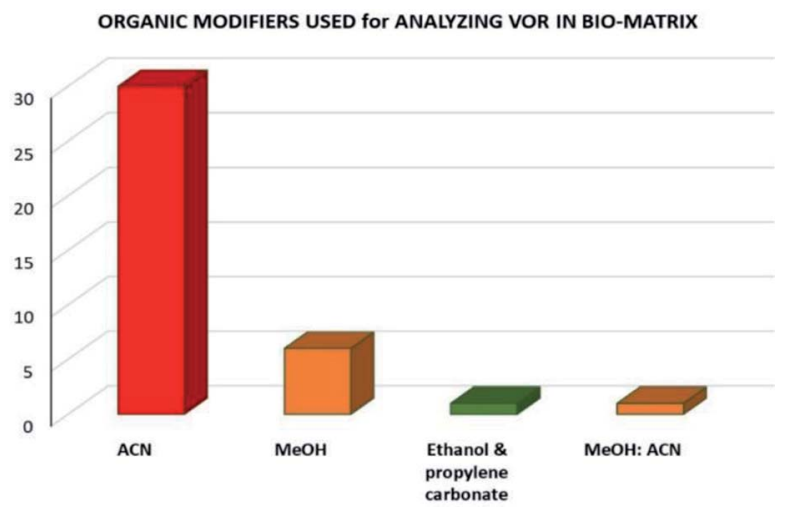

Fig. 6 Organic modifiers used in the developed methods for analyzing VOR in biological matrixes. 
extraction processes utilized in the analysis of VOR in bio samples. Mainly the reported methods were composed of toxic solvents rather than green solvents.

The NEMI tool shows that two methods were eco-friendly among the spectrophotometric methods that used water and buffer as a solvent, one in HPLC methods that utilized isopropyl alcohol and water as mobile phase, no methods were green reported by HPTLC, and one in bio-analytical method that utilized propylene carbonate as a mobile phase. NEMI concludes that miscellaneous methods like sweeping-micellar electrokinetic chromatography, DPP, PSMS, and microbiological methods are safe and supportable for the environment.

The GAPI tool results strengthen NEMI's assumption in spectrophotometric, HPTLC, and bioanalytical methods, but picked a UFLC method as the best eco-friendly one among the reported ones; GAPI also indicates that the PSMS and microbiological methods are safest compared to the other methods concluded by the NEMI.

Pictographic assessment of AES is a numerical assessment tool that gives conclusive evidence with the help of a specific value. AES results support the inference given by GAPI for spectrophotometric, HPTLC, HPLC, and reported bio-analytical methods and strengthen it with a numerical value. In miscellaneous methods, AES showed a very slight edge toward the microbial method and showed a score of 100 .

The final evaluation technique, AGREE, a very conclusive tool for green assessment, has confirmed the green-collar of the reported methods for greenness. AGREE has confirmed the method's greenness and supports AES's interpretation for spectrophotometric, HPTLC and reported bio-analytical methods but supported NEMI in the HPLC reported practices. Unlike AES, AGREE also showed a very slight edge toward the microbial process and showed a score of 0.95 .

But prior consideration by four assessment tools states that the microbial examination method has the most eco-friendly results followed by the PSMS. The only drawback of these methods was that one consumes time. The other utilized only tears as a sample, nullifying the sampling procedure concept as it is not recognized as a transferable method. Only one bioanalytical method ${ }^{\mathbf{1 2 5}}$ was eco-friendly, which utilized propylene carbonate as a solvent. The results indicate the importance of developing new green methods, which should be eco-friendly and easily applicable for industrial purposes.

Time is a crucial aspect for any industry in terms of production, as the quantity of production increases that directly enhances the effect of analysis time. So, it is always essential from an industrial point of view to consider an analytical method that can give the best results in less time by consuming less energy. Among the present methods for determination of VOR, the UV method consumes significantly less energy and time for analysis but has some flaws like reliability or reproducibility, whereas chromatographic methods are well adopted due to their several advantages. Among the chromatographic techniques, HPTLC is the most time and energy-consuming technique. LCMS and GCMS are the highly accurate methods for determinations but have a disadvantage like high energy consumption, which negatively affects the environment. The
RP-HPLC is the most affordable and reliable in most industries for the analysis of pharmaceuticals, but this also has a disadvantage like energy consumption. Finally, the UPLC method is the most advantageous due to its highly reliable results in less time. Here, the application of time indicates an added advantage to the industries and reduces the generation of harmful greenhouse substances into the environment.

\section{Conclusion}

According to the current review, the methodological approaches accessible for VOR determination comprise spectrophotometry, chromatography, and biological test methods. Each method has its own set of advantages and disadvantages when compared to others. As methods have been continuously developed to assess VOR, this drug's importance shows a need for a non-polluting methodology for drug analysis. Among the methods reported, only one approach has utilized more environmentally supportable practices, an introductory note for future research regarding this compound. Analysts and expert formulators must create more environmentally friendly techniques for estimating VOR that use less hazardous solvents. Additional LCMS/MS-based methods may quantify the medication in biological matrixes, which might be more critical for VOR therapeutic monitoring. Analytical quality by design, which was performed using Box-Behnken design, shows some supremacy among the methods due to long-term sustainability. AQbD deals with developing strategies for the future, but the drawback of the methods used to determine VOR is that they have not applied bio-degradable solvents. Therefore, incorporation of quality (AQbD) and eco-friendly (GAC) principles in developing techniques is highly recommended for the estimation of VOR in various matrixes, and more methods need to be developed to analyze VOR, which should be based on clean green analytical chemistry and make the environment and environment analyst safe.

\section{Future aspects}

The pharmaceutical and chemical industries are concerned about environmental safety and green analytical method development as a value in the vision of pharma industries 4.0. There is an opportunity to develop environmentally benign methods more positively by applying greener analytical techniques in analytical research and development via regular quality control activities. The future development of a stable green HPLC method with the aid of quality by design to estimate VOR without the need for revalidation would be more beneficial. There were no green HPLC methods for estimating VOR and its known and unknown impurities, and the same should be developed. The new transformation of extractions included using lower organic solvents, sorbents, better extraction and clean-up, fewer pre-treatment steps for a sample, and improved selectivity adoptions into the method development of bioanalytical matrixes more eco-friendly.

The new transformation of extractions included the usage of lower organic solvents, sorbents, better extraction and clean-up, 
fewer pre-treatment steps for a sample, and improved selectivity. Green microextraction technology is a user-friendly platform for analysts and far less environmentally damaging and provides even fewer toxic solvents, miniaturization, greater automation, and online coupling power with analysis techniques. Adopting these technologies for pharmaceutical analysis makes the method more stable, environmentally benign, and lasts longer.

Furthermore, no quantitative IR or NIR method was reported to estimate VOR, which should be developed and shall be the greenest method over LC and other methods and delivers the scope of developing quantitative IR methods to assess VOR.

\section{Conflicts of interest}

There are no conflicts to declare.

\section{References}

1 J. K. B. T. Aronson, Meyler's Side Effects of Drugs, Elsevier, Oxford, 16th edn, 2016, pp. 504-521.

2 A. L. Marano, J. Hooten and S. A. Myers, in Kidney Transplantation - Principles and Practice, Elsevier, 2019, pp. 578-590.

3 M. A. Keller and E. R. Stiehm, Clin. Microbiol. Rev., 2000, 13, 602-614.

4 N. D. Greer, Baylor University Medical Center Proceedings, 2003, 16, 241-248.

5 C.-Y. Low and C. Rotstein, F1000 Medicine Reports, 2011, 3, 14.

6 R. Olum, J. B. Baluku, A. Kazibwe, L. Russell and F. Bongomin, PLoS One, 2020, 15, e0240374.

7 J. Wang, M. Zhou, J.-Y. Xu, R.-F. Zhou, B. Chen and Y. Wan, JAMA Network Open, 2020, 3, e2017652.

8 D. Al-Badriyeh, C. F. Neoh, K. Stewart and D. C. M. Kong, Clin. Ophthalmol., 2010, 4, 391-405.

9 L. R. Snyder, J. J. Kirkland and J. W. Dolan, Introduction to modern liquid chromatography, John Wiley \& Sons, New Jersey, USA, 2011.

10 R. Hartman, R. Helmy, M. Al-Sayah and C. J. Welch, Green Chem., 2011, 13, 934-939.

11 US EPA, O. US EPA, defining hazardous waste: listed, characteristic and mixed radiological wastes, US EPA, https:/www.epa.gov/hw/defining-hazardous-waste-listedcharacteristic-and-mixed-radiological-wastes, accessed 5 April 2021.

12 M. M. Kirchhoff, Resour., Conserv. Recycl., 2005, 44, 237243.

13 G. Shepherd, in Encyclopedia of Toxicology, Elsevier, 2005, pp. 54-56.

14 P. T. Anastas, Crit. Rev. Anal. Chem., 1999, 29, 167-175.

15 L. H. Keith, L. U. Gron and J. L. Young, Chem. Rev., 2007, 107, 2695-2708.

16 P. T. Anastas and J. C. Warner, Green chemistry: theory and practice, Oxford University Press, Oxford [England], New York, 1998.
17 M. Koel and M. Kaljurand, Pure Appl. Chem., 2006, 78, 19932002.

18 A. Gałuszka, Z. Migaszewski and J. Namieśnik, TrAC, Trends Anal. Chem., 2013, 50, 78-84.

19 M. Tobiszewski, M. Marć, A. Gałuszka and J. Namieśnik, Molecules, 2015, 20, 10928-10946.

20 H. K. Chanduluru and A. Sugumaran, Acta Chromatogr., 2021, DOI: 10.1556/1326.2021.00949.

21 A. Ismael, A. Gevorgyan, T. Skrydstrup and A. Bayer, Org. Process Res. Dev., 2020, 24, 2665-2675.

22 S. N. Sawant, in Biopolymer Composites in Electronics, Elsevier, 2017, pp. 353-383.

23 B. A. Jones, J. Liq. Chromatogr. Relat. Technol., 2004, 27, 1331-1352.

24 M. Novotny, Clin. Chem., 1980, 26, 1474-1479.

25 J. M. Cunliffe and T. D. Maloney, J. Sep. Sci., 2007, 30, 31043109.

26 S. Chen and A. Kord, J. Chromatogr. A, 2009, 1216, 62046209.

27 M. Kaljurand and M. Koel, Crit. Rev. Anal. Chem., 2011, 41, 2-20.

28 S. Dulaurent, S. El Balkhi, L. Poncelet, J.-M. Gaulier, P. Marquet and F. Saint-Marcoux, Anal. Bioanal. Chem., 2016, 408, 1467-1474.

29 L. T. Taylor, J. Supercrit. Fluids, 2009, 47, 566-573.

30 R. M. Smith, J. Chromatogr. A, 2008, 1184, 441-455.

31 Y. Yang, J. Sep. Sci., 2007, 30, 1131-1140.

32 R. M. Smith, Anal. Bioanal. Chem., 2006, 385, 419-421.

33 J. Płotka-Wasylka, M. Rutkowska, K. Owczarek, M. Tobiszewski and J. Namieśnik, TrAC, Trends Anal. Chem., 2017, 91, 12-25.

34 Y. A. Olcer, M. Tascon, A. E. Eroglu and E. Boyacı, TrAC, Trends Anal. Chem., 2019, 113, 93-101.

35 F. Tache, S. Udrescu, F. Albu, F. Micăle and A. Medvedovici, J. Pharm. Biomed. Anal., 2013, 75, 230-238.

36 K. D. Clark, C. Zhang and J. L. Anderson, Anal. Chem., 2016, 88, 11262-11270.

37 K. P. Kannaiah and A. Sugumaran, Curr. Chem. Lett., 2022, 11, 11-22.

38 H.-A. H. Abd-ElSalam, M. Gamal, I. A. Naguib, M. A. AlGhobashy, H. E. Zaazaa and M. Abdelkawy, Separations, 2021, 8, 137.

39 S. Beg, J. Haneef, M. Rahman, R. Peraman, M. Taleuzzaman and W. H. Almalki, in Handbook of Analytical Quality by Design, Elsevier, 2021, pp. 1-14.

40 F. G. Vogt and A. S. Kord, J. Pharm. Sci., 2011, 100, 797-812. 41 T. Sharma, A. Jain, S. Saini, O. Katare and B. Singh, Sep. Sci. plus, 2020, 3, 384-398.

42 K. P. Kannaiah and A. Sugumaran, Journal of Taibah University for Science, 2021, 15, 1156-1167.

43 K. P. Kannaiah and A. Sugumaran, Microchem. J., 2022, 172, 106968.

44 H. Shaaban and A. Mostafa, J. AOAC Int., 2018, 101, 17811787.

45 Z. Li, K. H. Smith and G. W. Stevens, Chin. J. Chem. Eng., 2016, 24, 215-220. 
46 M. Tobiszewski and J. Namieśnik, Ecotoxicol. Environ. Saf., 2015, 120, 169-173.

47 D. Prat, O. Pardigon, H.-W. Flemming, S. Letestu, V. Ducandas, P. Isnard, E. Guntrum, T. Senac, S. Ruisseau, P. Cruciani and P. Hosek, Org. Process Res. Dev., 2013, 17, 1517-1525.

48 A. Astel, S. Tsakovski, P. Barbieri and V. Simeonov, Water Res., 2007, 41, 4566-4578.

49 J. Płotka-Wasylka, Talanta, 2018, 181, 204-209.

50 NFPA, List of nfpa codes and standards, https:// www.nfpa.org/Codes-and-Standards/All-Codes-andStandards/List-of-Codes-and-Standards, accessed 6 April 2021.

51 A. F. El-Yazbi, F. M. Aboukhalil, E. F. Khamis, R. M. Youssef and M. A. El-Sayed, Microchem. J., 2021, 163, 105900.

52 M. M. Ayad, M. M. Hosny, A. E. Ibrahim, O. M. El-Abassy and F. F. Belal, Acta Chromatogr., 2021, 33, 51-56.

53 N. Maljurić, B. Otašević, J. Golubović, J. Krmar, M. Zečević and A. Protić, Microchem. J., 2020, 153, 104394.

54 M. Gamal, I. A. Naguib, D. S. Panda and F. F. Abdallah, Anal. Methods, 2021, 13, 369-380.

55 J. Płotka-Wasylka and W. Wojnowski, Green Chem., 2021, 23, 8657-8665.

56 K. Kanaka Parvathi, A. Sugumaran, C. Hemanth Kumar and R. Seetharaman, Microchem. J., 2021, 106685.

57 S. A. E. A. Mohamed and F. F. Belal, Microchem. J., 2019, 148, 262-269.

58 F. Pena-Pereira, W. Wojnowski and M. Tobiszewski, Anal. Chem., 2020, 92, 10076-10082.

59 K. Kannaiah and A. Sugumaran, Quim. Nova, DOI: 10.21577/0100-4042.20170798.

60 Y. Gaber, U. Törnvall, M. A. Kumar, M. Ali Amin and R. Hatti-Kaul, Green Chem., 2011, 13, 2021-2025.

61 S. Saroj, V. Jairaj and R. Rathod, J. Liq. Chromatogr. Relat. Technol., 2017, 40, 340-352.

62 H. K. Chanduluru and A. Sugumaran, RSC Adv., 2021, 11, 27820-27831.

63 M. of H. Government of India, Pharmacopoeia of India: The Indian Pharmacopoeia, Manager of Publications, Delhi, 1st edn, 1955, 8th edn, 2018.

64 British Pharmacopoeia, British Pharrmacopoeia, British Pharmacopoeia, 9th edn, 2018.

65 USP, in USP, 2018, pp. 4336-4338.

66 G. S. Babu and C. A. I. Raju, Asian J. Chem., 2007, 19, 16251627.

67 N. Tamilselvi, T. Bhavanam, T. S. Thomas, D. S. Kurian, K. Sruthi, M. Sunkara and M. R. Deepthi, Res. J. Pharm. Technol., 2012, 5, 365-366.

68 S. Roy, B. V. V. Ravi Kumar and S. Tarafdar, Int. J. Pharm. Technol., 2011, 3, 1904-1912.

69 T. Deepan, V. Alekhya, P. Senniappan and M. Dhanaraju, Int. J. Chem. Pharm. Sci., 2014, 5, 164-167.

70 A. A. Gouda, R. El Sheikh, A. S. Amin and S. H. Ibrahim, Int. J. Pharm. Pharm. Sci., 2015, 7, 126-133.

71 B. K. R. K. Raghubabu and V. Jagannadharao, Asian J. Res. Chem., 2012, 5, 595-599.
72 K. Lingamaneni and M. M. Annapurna, Res. J. Pharm. Technol., 2021, 14, 420-426.

73 N. Üstündağ Okur, E. Ş. Çağlar and V. Yozgatlı, Marmara Pharm. J., 2016, 20, 79-85.

74 A. I. H. Adams and A. M. Bergold, Chromatographia, 2005, 62, 429-434.

75 A. Nagarjuna, K. Padmaja Reddy, K. Mukkanti and M. V. Suryanarayana, Chromatographia, 2007, 66, 439-441.

76 X. Huang, F. Qiu and S. Cheng, Chromatographia, 2008, 68, 649-652.

77 D. Gowri Sankar, A. Nagesh Babu, A. Rajeswari and M. Vamsi Krishna, Asian J. Chem., 2009, 21, 5015-5018.

78 M. C. D. A. R. M. A. B. Khetre and P. K. Sinha, Indian J. Pharm. Sci., 2009, 8, 67-79.

79 P. Gu and Y. Li, J. Chromatogr. Sci., 2009, 47, 594-598.

80 V. M. R. V. V. Wamorkar, C. S. Ramaa and S. Y. Manjunath, Int. J. Pharm. Sci. Nanotechnol., 2010, 3, 978-985.

81 A. Ibrahim, B. Eldin, A. Ibrahim, B. Eldin and A. Shalaby, Eurasian J. Anal. Chem., 2010, 5, 254-264.

82 M. B. Saidulu Goli and N. Sriram, Int. J. Med. Chem. Anal., 2013, 3, 6-9.

83 J. Y. Sreeramamurthy Pyla, K. Srinivas, J. Panda and P. S. Rose, Chem. Sci. Trans., 2014, 3, 1576-1582.

84 T. D. J. Srinivas and M. Srinivas, Saudi J. Med. Pharm. Sci., 2015, 1, 70-79.

85 I. A. M. Swapna Singh and G. Goyal, International Journal of All Research Writings, 2019, 1, 40-50.

86 K. A. Shaikh and A. T. Patil, Sci. Pharm., 2012, 80, 879-888.

87 A. B. Khetre, R. S. Darekar, P. K. Sinha, R. M. Jeswani and M. C. Damle, Rasayan J. Chem., 2008, 1, 542-547.

88 G. D. Mohit, T. C. Borole, S. P. Gandhi and A. R. Madgulkar, Der Pharma Chemica, 2011, 3, 201-209.

89 M. W. Jain, A. A. Shirkhedkar and S. J. Surana, Arabian J. Chem., 2017, 10, S355-S360.

90 V. Gandhi Santosh, A. Kadam Ashwini and A. Suralkar Manjula, Int. J. Res. Pharm. Chem., 2014, 4, 564-570.

91 L. Zhou, R. D. Glickman, N. Chen, W. E. Sponsel, J. R. Graybill and K. W. Lam, J. Chromatogr. B: Anal. Technol. Biomed. Life Sci., 2002, 776, 213-220.

92 M. Vogeser, X. Schiel and U. Spöhrer, Clin. Chem. Lab. Med., 2005, 43, 730-734.

93 D. A. Stopher and R. Gage, J. Chromatogr. B: Biomed. Sci. Appl., 1997, 691, 441-448.

94 R. Gage and D. A. Stopher, J. Pharm. Biomed. Anal., 1998, 17, 1449-1453.

95 M. G. Rinaldi, G. J. Pennick, M. Clark and D. A. Sutton, Antimicrob. Agents Chemother., 2003, 47, 2348-2350.

96 F. Péhourcq, C. Jarry and B. Bannwarth, Biomed. Chromatogr., 2004, 18, 719-722.

97 M. Wenk, A. Droll and S. Krähenbühl, J. Chromatogr. B: Anal. Technol. Biomed. Life Sci., 2006, 832, 313-316.

98 M. Vogeser, X. Schiel and U. Spöhrer, Clin. Chem. Lab. Med., 2005, 43, 730-734.

99 B. V. Araujo, D. J. Conrado, E. C. Palma and T. Dalla Costa, J. Pharm. Biomed. Anal., 2007, 44, 985-990.

100 S. Cheng, J. Huang and J. He, Pharmazie, 2007, 62, 577-579. 
101 Z. K. Shihabi, J. Liq. Chromatogr. Relat. Technol., 2008, 31, 263-268.

102 A. Pascual, V. Nieth, T. Calandra, J. Bille, S. Bolay, L. A. Decosterd, T. Buclin, P. A. Majcherczyk, D. Sanglard and O. Marchetti, Antimicrob. Agents Chemother., 2007, 51, 137-143.

103 L. J. Langman and F. Boakye-Agyeman, Clin. Biochem., 2007, 40, 1378-1385.

104 C. Michael, J. Teichert and R. Preiss, J. Chromatogr. B: Anal. Technol. Biomed. Life Sci., 2008, 865, 74-80.

105 F. Simmel, J. Soukup, A. Zoerner, J. Radke and C. Kloft, Anal. Bioanal. Chem., 2008, 392, 479-488.

106 J. Steinmann, J. Huelsewede, J. Buer and P. M. Rath, Mycoses, 2011, 54, 421-428.

107 L. Zhou, R. D. Glickman, N. Chen, W. E. Sponsel, J. R. Graybill and K.-W. Lam, J. Chromatogr. B: Anal. Technol. Biomed. Life Sci., 2002, 776, 213-220.

108 D. Lin, G. Li and L. Chen, J. Chromatogr. Sci., 2013, 51, 482489.

109 J. Mak, K. K. Sujishi and D. French, J. Chromatogr. B: Anal. Technol. Biomed. Life Sci., 2015, 986-987, 94-99.

110 M. ter Avest, A. Veringa, K. van Hateren, R. A. Koster, D. J. Touw and J.-W. Alffenaar, J. Appl. Bioanal., 2018, 4, 114-123.

111 E. Cendejas-Bueno, J. L. Rodríguez-Tudela, M. CuencaEstrella and A. Gómez-López, Enfermedades Infecciosas $y$ Microbiología Clínica, 2013, 31, 23-28.

112 S. Prommas, A. Puangpetch, N. Jenjirattithigarn, S. Chuwongwattana, T. Jantararoungtong, N. Koomdee, S. Santon, M. Chamnanphon and C. Sukasem, J. Clin. Lab. Anal., 2017, 31, 1-7.

113 P. H. Tang, Global J. Med. Res., 2017, 17, 292-300.

114 Q. U. A. Ambreen Rehman, N. Asif, A. Hafeez, A. Ijaz and M. Waseem, Pakistan Armed Forces Medical Journal, 2019, 69, 516-521.

115 M. Resztak, K. Kosicka, P. Zalewska, J. Krawiec and F. K. Główka, J. Pharm. Biomed. Anal., 2020, 178, 112952.

116 H. Mei, X. Hu, J. Wang, R. Wang and Y. Cai, Int. J. Med. Res., 2020, 48, 030006051988701.

117 H. Liu, Y. Wang, N. Wang, M. Liu and S. Liu, Chemom. Intell. Lab. Syst., 2019, 193, 103833.
118 S. Yousefian, F. Dastan, M. Marjani, P. Tabarsi, S. Barati, N. Shahsavari and F. Kobarfard, Canadian Journal of Infectious Diseases and Medical Microbiology, 2021, 2021, $1-6$.

119 Y. Wen, S. Chen, Y. Yuan, Q. Shao, X. He and H. Qiao, Acta Chromatogr., 2021, 34(2), 162-169.

120 G. A. Khoschsorur, F. Fruehwirth and S. Zelzer, Antimicrob. Agents Chemother., 2005, 49, 3569-3571.

121 S. Chhun, E. Rey, A. Tran, O. Lortholary, G. Pons and V. Jullien, J. Chromatogr. B: Anal. Technol. Biomed. Life Sci., 2007, 852, 223-228.

122 K. Kahle, P. Langmann, D. Schirmer, U. Lenker, D. Keller, A. Helle, H. Klinker and W. J. Heinz, Antimicrob. Agents Chemother., 2009, 53, 3140-3142.

123 L. Baietto, A. D'Avolio, G. Ventimiglia, F. G. De Rosa, M. Siccardi, M. Simiele, M. Sciandra and G. Di Perri, Antimicrob. Agents Chemother., 2010, 54, 3408-3413.

124 Y. Xiao, Y. K. Xu, P. Pattengale, M. R. O'Gorman and X. Fu, J. Appl. Lab. Med., 2017, 1, 626-636.

125 A. Dogan and N. E. Basci, Curr. Pharm. Anal., 2017, 13(6), 495-504.

126 N. Jenkins, M. Black and H. G. Schneider, Clin. Biochem., 2018, 53, 110-115.

127 R. a. Xu, Q. Lin, X. Qiu, J. Chen, Y. Shao, G. Hu and G. Lin, J. Pharm. Biomed. Anal., 2019, 166, 6-12.

128 G. Srinubabu, C. A. I. Raju, N. Sarath, P. K. Kumar and J. V. L. N. S. Rao, Talanta, 2007, 71, 1424-1429.

129 S. C. Lin, S. W. Lin, J. M. Chen and C. H. Kuo, Talanta, 2010, 82, 653-659.

130 G. Corbini, A. Zanfini, C. Rosa, A. D'Arpino, R. Meucci and E. Dreassi, Curr. Anal. Chem., 2009, 5, 238-243.

131 A. Smith and V. Leung-Pineda, J. Clin. Lab. Anal., 2016, 30, 411-417.

132 M. Lerch, R. A. Allbaugh, L. Sebbag, J. P. Mochel, P. Weller and D. J. Borts, Anal. Bioanal. Chem., 2019, 411, 5187-5196.

133 M. Sahitya, S. Fathima, A. Divya, K. Vaishali, M. NidhiSree, C. Spandana Reddy, T. S. Ramya, S. Rani, Y. Padmavathi and R. Kiran, J. Young Pharm., 2020, 12, s113-s116.

134 R. Kaur, S. Saini, T. Sharma, O. Katare, A. Kaushik and B. Singh, Anal. Chem. Lett., 2021, 11, 168-186. 